\title{
Sedimentary and mineral dust sources of dissolved iron to the world ocean
}

\author{
J. K. Moore ${ }^{1}$ and O. Braucher ${ }^{1,2}$ \\ ${ }^{1}$ University of California, Irvine, Department of Earth System Science, Irvine, CA 92697-3100, USA \\ ${ }^{2}$ now at: Humboldt State University, Arcata, CA, 95521, USA
}

Received: 22 March 2007 - Published in Biogeosciences Discuss.: 25 April 2007

Revised: 18 April 2008 - Accepted: 18 April 2008 - Published: 5 May 2008

\begin{abstract}
Analysis of a global compilation of dissolved-iron observations provides insights into the processes controlling iron distributions and some constraints for ocean biogeochemical models. The distribution of dissolved iron appears consistent with the conceptual model developed for Th isotopes, whereby particle scavenging is a two-step process of scavenging mainly by colloidal and small particulates, followed by aggregation and removal on larger sinking particles. Much of the dissolved iron $(<0.4 \mu \mathrm{m})$ is present as small colloids $(>\sim 0.02 \mu \mathrm{m})$ and, thus, is subject to aggregation and scavenging removal. This implies distinct scavenging regimes for dissolved iron consistent with the observations: 1) a high scavenging regime - where dissolved-iron concentrations exceed the concentrations of strongly binding organic ligands; and 2) a moderate scavenging regime where dissolved iron is bound to both colloidal and soluble ligands. Within the moderate scavenging regime, biological uptake and particle scavenging decrease surface iron concentrations to low levels $(<0.2 \mathrm{nM})$ over a wide range of low to moderate iron input levels. Removal rates are also highly nonlinear in areas with higher iron inputs. Thus, observed surface-iron concentrations exhibit a bi-modal distribution and are a poor proxy for iron input rates. Our results suggest that there is substantial removal of dissolved iron from subsurface waters (where iron concentrations are often well below $0.6 \mathrm{nM}$ ), most likely due to aggregation and removal on sinking particles of Fe bound to organic colloids.

We use the observational database to improve simulation of the iron cycle within a global-scale, Biogeochemical Elemental Cycling (BEC) ocean model. Modifications to the model include: 1) an improved particle scavenging parameterization, based on the sinking mass flux of particulate organic material, biogenic silica, calcium carbonate, and min-
\end{abstract}

Correspondence to: J. K. Moore (jkmoore@uci.edu) eral dust particles; 2) desorption of dissolved iron from sinking particles; and 3) an improved sedimentary source for dissolved iron. Most scavenged iron (90\%) is put on sinking particles to remineralize deeper in the water column. The model-observation differences are reduced with these modifications. The improved BEC model is used to examine the relative contributions of mineral dust and marine sediments in driving dissolved-iron distributions and marine biogeochemistry. Mineral dust and sedimentary sources of iron contribute roughly equally, on average, to dissolved iron concentrations. The sedimentary source from the continental margins has a strong impact on open-ocean iron concentrations, particularly in the North Pacific. Plumes of elevated dissolved-iron concentrations develop at depth in the Southern Ocean, extending from source regions in the SW Atlantic and around New Zealand. The lower particle flux and weaker scavenging in the Southern Ocean allows the continental iron source to be advected far from sources. Both the margin sediment and mineral dust Fe sources substantially influence global-scale primary production, export production, and nitrogen fixation, with a stronger role for the dust source. Ocean biogeochemical models that do not include the sedimentary source for dissolved iron, will overestimate the impact of dust deposition variations on the marine carbon cycle. Available iron observations place some strong constraints on ocean biogeochemical models. Model results should be evaluated against both surface and subsurface $\mathrm{Fe}$ observations in the waters that supply dissolved iron to the euphotic zone.

\section{Introduction}

Bruland et al. (1994) suggested that mineral dust supply of dissolved iron to open-ocean surface waters accounts for elevated mixed layer concentrations overlying an iron-depleted euphotic zone. They estimated a residence time for dissolved

Published by Copernicus Publications on behalf of the European Geosciences Union. 
iron in the deep ocean of 70-140 years, based on data from the central North Pacific, noting that substantial scavenging removal of iron must occur both in surface waters and in the deep ocean. In a seminal paper, Johnson et al. (1997a) compiled dissolved-iron observations from the North Pacific and several additional regions and drew some important conclusions: 1) there are similar concentrations throughout the deep ocean with no inter-ocean differences; 2) iron cycles differently than other highly particle reactive species, probably due to its complexation with organic ligands, which acts to protect iron from removal by scavenging; 3 ) the continental source for dissolved iron can extend far offshore in the deeper ocean $(1000 \mathrm{~m})$ but is removed from surface waters close to shore; 4) dissolved iron concentrations are consistently low in the surface ocean $(<0.2 \mathrm{nM})$. They suggested that the observed iron profiles could be generated by remineralization of a sinking biological particle flux with a mean iron/carbon ratio of $\sim 5 \mu \mathrm{mol} / \mathrm{mol}$, and particle scavenging removal of iron only where concentrations exceeded $\sim 0.6 \mathrm{nM}$ (and the protection of the strong iron-binding ligands). They also noted a significant but relatively weak correlation between estimated dust deposition and integrated dissolved iron in the upper $500 \mathrm{~m}$. Most of their observations came from relatively low dust deposition regions in the North Pacific and Southern Ocean.

In the same journal issue, there were several comments on the Johnson et al. (1997a) paper. Boyle (1997) suggested that dissolved iron distributions in the deep ocean were more varied than implied by the Johnson et al. (1997a) dataset, and that the impact of atmospheric deposition was more substantial than suggested. These suggestions have been corroborated by subsequent studies showing substantially elevated iron concentrations at the surface and in the deeper ocean beneath the major dust plumes (i.e., $\mathrm{Wu}$ and Boyle, 2002; Sedwick et al., 2005) and deep-ocean values well below $0.6 \mathrm{nM}$ throughout much of the Southern Ocean (i.e., Measures and Vink, 2001; de Baar et al., 1999; Coale et al., 2005). Sunda (1997) suggested that variations in phytoplankton $\mathrm{Fe} / \mathrm{C}$ ratios might play a substantial role, and estimated the $\mathrm{Fe} / \mathrm{C}$ ratios in sinking material remineralized in several regions. Those ratios ranged from $\sim 2 \mu \mathrm{mol} / \mathrm{mol}$ in the ironlimited Equatorial Pacific and Southern Ocean regions, to higher values of $7-13 \mu \mathrm{mol} / \mathrm{mol}$ in the high-latitude North Atlantic. This analysis assumed minimal subsurface scavenging of dissolved iron; iron removal by such scavenging would imply a higher ratio in regenerated material. In addition, much higher $\mathrm{Fe} / \mathrm{C}$ ratios in sinking material in the high dust deposition regions would seem necessary to remove excess iron from surface waters. Wu and Boyle (2002) estimated $\mathrm{Fe} / \mathrm{C}$ export regeneration ratios for the North Atlantic of 23-70 $\mu \mathrm{molFe} / \mathrm{molC}$. Lastly, Luther and Wu (1997) suggested iron concentrations will always be set by a balance between sources and sinks, with organic complexation playing a role. They noted that the decrease in surface-iron concentrations moving away from the coast was strongly influenced by the width of the shelf due to sediment resuspension events, which released dissolved iron into the water column (see also Chase et al., 2005). In their conceptual model, Johnson et al. (1997a) assumed that there was no particle scavenging of dissolved iron when the concentration was below $0.6 \mathrm{nM}$ due to the presence of strong, iron-binding ligands. This assumption was built into a number of ecosystem-biogeochemical models (i.e., Archer and Johnson, 1999; Lefèvre and Watson, 1999; Aumont et al., 2003). However, in their reply to the comments, Johnson et al. (1997b) noted that scavenging would not actually be eliminated at low iron concentrations, as there would always be a small fraction of the iron present as inorganic ions subject to scavenging. Thus, where inputs of dissolved iron are quite low, dissolved concentrations could be reduced below the $0.6 \mathrm{nM}$ value. A number of recent ecosystem models allow scavenging removal of iron at concentrations below 0.6 nM (Moore et al., 2002, 2004; Parekh et al., 2004; Aumont and Bopp, 2006).

In a comprehensive review of iron observations, de Baar and de Jong (2001) noted a substantial influence by continental iron sources extending offshore in many regions. They also noted consistently higher iron concentrations $(>1 \mathrm{nM})$ in low- $\mathrm{O}_{2}$ regions and below the major dust plumes. Low deep-water values were noted for the Southern Ocean $(\sim 0.3-$ $0.4 \mathrm{nM}$ ). They noted that surface values for the open ocean were variable $(0.03-0.5 \mathrm{nM})$ and ranged between 0.3 and $1.4 \mathrm{nM}$ for the deep ocean away from continental influence, with much higher values observed near the coastlines.

Several recent papers have suggested that the iron from continental margin sediments may substantially impact global iron distributions, including production and export far offshore. In the Southern Ocean, rapid advection of iron from sedimentary sources in the SW Atlantic within the Antarctic Polar Front was suggested to account for high iron concentrations measured along $6^{\circ} \mathrm{W}$ (de Baar et al., 1995; Löscher et al., 1997). Johnson et al. (2003) noted that the influence of the continental iron source extended well into the North Pacific subtropical gyre. Elrod et al. (2004) estimated a very large input of dissolved iron from continental shelf sediments

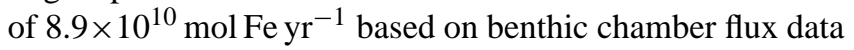
(Berelson et al., 1996, 2003). They suggested the sedimentary source is at least as large as the inputs of soluble iron from mineral dust, and that the continental shelf influence extends hundreds of $\mathrm{km}$ offshore. They also found a strong relationship between iron release and organic carbon oxidation in sediments, indicating that sediments beneath productive regions should release more dissolved iron (Elrod et al., 2004). Johnson et al. (2005) found strong offshore transport of dissolved iron by eddies into the gulf of Alaska. Lam et al. (2006) found evidence for offshore advection of particulate and dissolved iron from the margin over $900 \mathrm{~km}$ to Station P in the Gulf of Alaska. River inputs are thought to contribute a relatively small flux of dissolved iron to the oceans (de Baar and de Jong, 2001), but their inputs may be substantial in some regions where large rivers discharge to 
the shelf (Tovar-Sanchez et al., 2006).

Martin and coworkers argued that iron was a key limiting nutrient in the oceans, controlling biological production in the High-Nitrate, Low-Chlorophyll (HNLC) regions of the Southern Ocean, and in the subarctic and equatorial Pacific (Martin et al., 1991; Martin, 1992). Subsequent in situ ironfertilization experiments have demonstrated this iron limitation (Coale et al., 1996, 2004; Boyd et al., 2000; Tsuda et al., 2003) and have generally confirmed that the entire plankton community is iron limited. The bloom forming diatoms are strongly iron limited, whereas the ambient community, dominated by small phytoplankton, is moderately iron stressed and experiences strong grazing pressure (Price et al., 1994; see review by de Baar et al., 2005). Model estimates suggest community growth is limited by iron over $\sim 30-50 \%$ of the world ocean (Moore et al., 2002b, 2004; Aumont et al., 2003; Dutkiewicz et al., 2005). Observations also suggest that dissolved iron may limit phytoplankton growth rates near the base of the euphotic zone in the subtropical gyres (Bruland et al., 1994; Johnson et al., 1997; Sedwick et al., 2005). In addition, in many subtropical regions the diazotrophs (nitrogen fixers) may be limited by iron (Falkowski, 1997; Michaels et al., 2001; Berman-Frank et al., 2001; Moore et al., 2004, 2006). This iron requirement for nitrogen fixation may give the subtropics and tropics a sensitivity to atmospheric dust (iron) inputs similar to that seen in the HNLC regions (Michaels et al., 2001; Gruber, 2004). Model estimates indicate that the indirect, nitrogen-fixation-driven biogeochemical response to dust variations can be quantitatively similar to the more direct response in the HNLC regions in terms of total export production and air-sea $\mathrm{CO}_{2}$ exchange over decadal timescales (Moore et al., 2006). Thus, iron may be the ultimate limiting nutrient for the oceans in the current climate, directly limiting growth in the HNLC regions and leading to nitrogen being the proximate limiting nutrient in other areas (Moore and Doney, 2007).

Dissolved iron is removed from ocean surface waters through biological uptake and through abiotic particle scavenging (adsorption to and removal on sinking particles). Much of our understanding about particle scavenging in the oceans comes from studies of Th isotopes produced by radioactive decay and not subject to biological uptake. Iron and aluminum are probably scavenged in a similar manner, so Th studies have implications for understanding the cycling of these trace metals (Bruland and Lohan, 2004). The conceptual view developed in recent decades is that removal of particle-reactive species like ${ }^{234} \mathrm{Th}$ is actually a two-stage process with reversible adsorption, mainly to smaller and colloidal sized particles, followed by aggregation and removal on larger sinking particles (Balistrieri et al., 1981; Bacon and Anderson, 1982; Honeyman et al., 1988; Clegg and Sarmiento, 1989; Honeyman and Santschi, 1989; Wells and Goldberg, 1993; Santschi et al., 2006; see review by Savoye et al., 2006). Models of dissolved Th removal by particle scavenging range from simple models, with a net adsorption rate to sinking particles, to more complex models that represent the particle size spectrum down to colloids and explicitly represent adsorption, desorption, aggregation, and removal processes (Burd et al., 2000; Bruland and Lohan, 2004; see review by Savoye et al., 2006, and references therein). There is still debate as to the significance of desorption of Th from particles (Quigley et al., 2001; Santschi et al., 2006).

De Baar and de Jong (2001) noted that the "dissolved" iron measured after passing through a $0.4 \mu \mathrm{M}$ filter is actually a mix of iron bound to truly dissolved (soluble) ligands $(<0.025 \mu \mathrm{M})$ and iron bound to fine particulates (colloids $<0.4 \mu \mathrm{M})$. They suggested a dynamic, quasi-equilibrium shifting iron between organic, inorganic, soluble and colloidal pools. This equilibrium would be strongly influenced by photochemistry and the biota, which serves as the source of both the ligands and particles that scavenge iron during export events. In the deep ocean, scavenging loss rates would be determined largely by the partitioning between colloidal and dissolved phases, with longer residence times where more Fe was bound by soluble ligands. Wu et al. (2001) studied this division between soluble $(<0.02 \mu \mathrm{M})$ and colloidal iron ( $>0.02 \mu \mathrm{M}$ and $<0.4 \mu \mathrm{M}$ ) using profiles in the subtropical North Pacific and North Atlantic. They found that much of the dissolved iron was present in the colloidal fraction in surface and deep-ocean waters, with a colloidal iron minimum in the upper nutricline. They suggested that aggregation and sinking removal of the colloidal fraction would occur in a manner similar to $\mathrm{Th}$, and that this process should be included in models of oceanic iron cycling. Nishioka et al. (2001) noted considerable temporal and spatial variability in soluble and colloidal iron concentrations, suggesting a dynamic system. Cullen et al. (2006) built on this work with several profiles in the Atlantic, examining soluble vs. colloidal fractions of dissolved iron and the ligands that bind iron. They concluded that much of the partitioning of iron between colloidal and soluble pools could be understood by a simple equilibrium partitioning model, but that a substantial and varying fraction of the colloidal material was not affected by ligand exchange with the soluble pool. These studies suggest that the soluble iron may be more bioavailable than thought previously, as vertical distributions were more like traditional nutrient profiles.

If particle scavenging of iron happens in a manner similar to Th scavenging (as seems probable), there are important implications for iron cycling in the oceans. Binding to ligands will not provide complete protection from particle scavenging removal (as sometimes assumed in biogeochemical models), because the colloidal fraction will be subject to removal by aggregation and scavenging. Only the truly soluble fraction would be largely "protected" from scavenging. The colloid-bound iron would have reduced rates of scavenging loss compared with unbound inorganic iron. This free inorganic iron is dwarfed by the dissolved pool $(<\sim 1 \%)$, as most dissolved iron is bound to organic ligands (i.e. Rue and Bruland, 1995, 1997; van den Berg, 1995; Wu and 
Luther, 1995). The particle scavenging removal rate for dissolved iron would then be a function of the proportions in the soluble versus colloidal pools, the dynamics of the particle size distributions and aggregation removal processes, and the transfer time of dissolved iron between the various forms.

Iron has been incorporated as a limiting nutrient for phytoplankton growth in a number of global-scale ocean biogeochemical models (Archer and Johnson, 1999; Moore et al., 2002, 2004; Aumont et al., 2003; Gregg et al. 2004; Parekh et al., 2004, 2005; Doney et al., 2006). These efforts were facilitated by a growing understanding of iron cycling in the oceans, the result of numerous field campaigns, including those associated with the international Joint Global Ocean Flux Study, and the iron fertilization experiments (see Doney and Ducklow, 2006; and de Baar et al., 2005; and references therein). The treatment of iron in these models is still rudimentary, often with a single dissolved pool and often with no explicit iron-ligand interactions, due to the large uncertainties associated with the sources and sinks of iron-binding ligands, the relative bioavailability of ligand-bound iron, and the interaction of ligands with particle scavenging removal of dissolved iron (some ligand dynamics are included in Parekh et al., 2004, 2005; Doney et al., 2006; and Aumont and Bopp, 2006). Parekh et al. (2004) examined three different models of iron cycling in the context of an ocean box model that included: 1) net scavenging onto particles, 2) scavenging and desorption, and 3) explicit ligand complexation, with a globally uniform ligand concentration at $1 \mathrm{nM}$, that applied scavenging only to the free Fe.

It has been recognized that the flux of iron from sediments, including sediment resuspension events, leads to high iron concentrations in coastal waters (Luther and Wu, 1997; Johnson et al., 1999; Chase et al., 2005). However, it has generally been assumed that dissolution from mineral dust was the main source of dissolved iron to the open ocean (i.e., Jickells et al., 2005), particularly in the development of ocean biogeochemical models, most of which include only a dust source for dissolved iron (Archer and Johnson, 1999; Aumont et al., 2003; Gregg et al., 2004; Parekh et al., 2004, 2005). Moore et al. (2004) included a constant sedimentary iron source of $2 \mu \mathrm{mol} \mathrm{Fe} \mathrm{m}{ }^{-2}$ day $^{-1}$ in areas where depth was less than $1100 \mathrm{~m}$. However, due to the coarse grid resolution and the necessary strong smoothing of ocean bathymetry, this iron source was often too deep to influence surface ocean biogeochemistry, even in grid locations directly adjacent to the continents (Moore et al., 2004). Thus, the biogeochemical impact of this iron source was greatly underestimated. Aumont and Bopp (2006) addressed this problem by specifying a sedimentary iron source in each grid cell based on a high resolution ocean bathymetry, rather than the bathymetry of the circulation model grid (an approach we adopt here).

We present a new compilation of existing data for dissolved iron throughout the world ocean, noting a strong apparent influence of the sedimentary iron source with high values near the continental margins and steadily decreasing offshore. We also utilize this observational database to evaluate and constrain key aspects of iron cycling in the Biogeochemical Elemental Cycling (BEC) model, which includes several key phytoplankton functional groups (diatoms, coccolithophores, diazotrophs, and picoplankton) and the biogeochemical cycles of key elements (C, N, P, Fe, Si, and O, Moore et al., 2004). The observational database is used to evaluate and constrain the model. We then use the improved model, which includes an improved sedimentary source for dissolved iron, to examine the relative roles of the sedimentary and mineral dust sources for dissolved iron in driving oceanic dissolved iron distributions and the marine biogeochemical cycles of carbon and nitrogen.

\section{Methods}

\subsection{The observational database}

We analyze field observations of dissolved iron concentrations and compare with simulated iron distributions from the BEC ocean model. The original iron database was complied by Parekh et al. (2005) and has been expanded by 30\% (to 6540 data points) with data from recent publications. Many of these values are the reported means from duplicate or triplicate samples at a particular depth. Parekh et al. (2005) collected data from the literature and three previous key compilations of iron observations (Johnson et al., 1997; de Baar and de Jong, 2001; Gregg et al., 2003). Some of the data included are dissolved-iron concentrations (filter size ranging from $0.2-0.45 \mu \mathrm{m}$ ) and the date, location, and depth of sampling. We have included only dissolved-iron measurements, not total dissolvable iron. The complete dataset with references to the original source articles is available as supplementary material to this article (http://www.biogeosciences. net/5/631/2008/bg-5-631-2008-supplement.zip). There may be systematic differences in the iron measurements by groups using different techniques. Ongoing inter-comparison efforts are reducing these differences (Bowie et al., 2003, 2006; and the recent SAFE cruise). Here we make the simplifying assumption that the strong vertical and basin-scale gradients in dissolved iron of interest in this work are larger than these systematic differences.

One focus in this work is evaluating the iron cycle parameterizations in the BEC model for both open-ocean regions where atmospheric dust deposition may be the dominant source of dissolved iron, and in regions near the continental margins having dominant sedimentary sources. We have created a subset of the iron database where we attempt to exclude data points strongly influenced by iron coming from non-dust sources including the continental margins and shelf sediments. As a first step we removed data from all ocean model grid cells adjacent to land. This removed much of the observed high-iron concentrations associated 
with continental sedimentary sources. However, in some regions it was apparent that the margin influence extended for some distance out into the open ocean, particularly at depth, away from the enhanced particle scavenging and biological uptake in the upper ocean.

In Fig. 1, we plot the dissolved-iron observations ( $>1000 \mathrm{~m}$ depth) from the eastern subtropical Pacific (latitudes $20-50^{\circ} \mathrm{N}$ ) as a function of approximate distance from the continent. The obvious decline in iron concentrations with distance from the margin has been noted previously (Johnson et al., 1997, 2003). The data points within $200 \mathrm{~km}$ of the coastline were removed by our land-adjacent rule in the margin-excluded dataset. In addition, we removed all data from the locations in Fig. 1 that are $\sim 550-700 \mathrm{~km}$ offshore, retaining the other data points as more representative of the open ocean. However, there may be influence of the continental margin even more than $1000 \mathrm{~km}$ offshore. Through a similar analysis, data was removed from several locations near the Asian coast in the NW Pacific. We also exclude data from several papers that measured high-iron concentrations attributed to sources not included in the BEC model (riverine or hydrothermal - Mackey et al., 2002; Kerguelen Islands runoff and sediments - Blain et al., 2001; Bucciarelli et al., 2001; and rapid advection from continental sources by the Antarctic Polar Front - Löscher et al., 1997). These steps removed $\sim 48 \%$ of the observations, leaving 3176 observations in our open-ocean subset (hereafter referred to as the "open ocean" data). This open-ocean subset is certainly more impacted by dust and less impacted by sedimentary iron sources than the excluded data. However, the model results presented here suggest that even these openocean iron concentrations are substantially influenced by the continental sedimentary source of iron.

\subsection{BEC model overview}

The coupled biogeochemical elemental cycling (BEC) model (Moore et al., 2002a, 2004) includes ecosystem and biogeochemistry components, including full carbonate-chemistry dynamics. The model includes four functional groups of phytoplankton (diatoms, coccolithophores, diazotrophs, and picophytoplankton) and multiple limiting nutrients (nitrate, ammonium, phosphate, silicate, and dissolved iron). The phytoplankton groups have a variable $\mathrm{Fe} / \mathrm{C}$ ratio that changes dynamically as a function of ambient dissolved iron concentrations, allowing a decrease in the ratio under low iron concentrations. The optimum $\mathrm{Fe} / \mathrm{C}$ ratio is set at $6 \mu \mathrm{mol} / \mathrm{mol}$ for all groups except the diazotrophs, which have a higher ratio of $40 \mu \mathrm{mol} / \mathrm{mol}$. These ratios can decline to values of $2.5 \mu \mathrm{mol} / \mathrm{mol}$ and $15 \mu \mathrm{mol} / \mathrm{mol}$ under strongly ironlimiting conditions (see Moore et al., 2004 for details). The BEC model runs within the coarse resolution, POP ocean model that is part of the Community Climate System Model (CCSM3.0) developed at the National Center for Atmospheric Research (Collins et al., 2006). The model includes

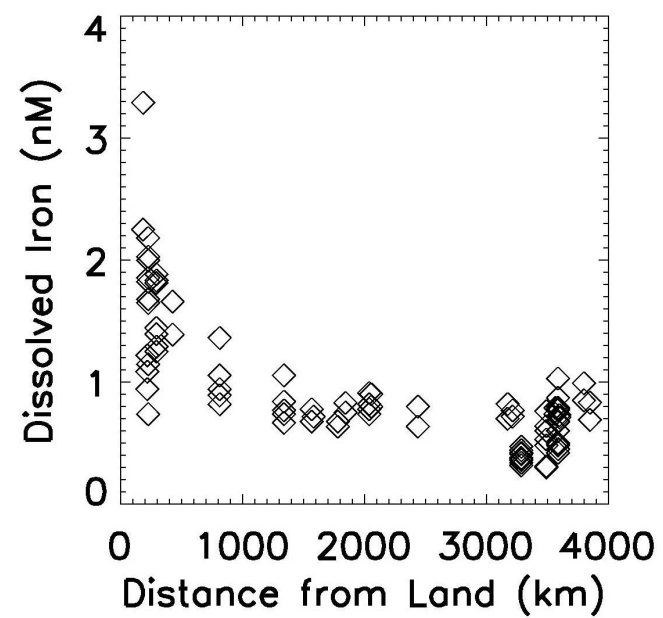

Fig. 1. Observed-iron concentrations from depths greater than $1000 \mathrm{~m}$ in the eastern subtropical Pacific Ocean $\left(20-50^{\circ} \mathrm{N}\right)$ plotted as a function of distance to the continental land mass.

25 vertical levels, with 8 levels in the upper $103 \mathrm{~m}$, a longitudinal resolution of 3.6 degrees, and a variable latitudinal resolution, from 2 degrees at high latitudes to finer resolution near the equator (Collins et al., 2006; Yeager et al., 2006). All the nutrients and elements $(\mathrm{C}, \mathrm{O}, \mathrm{N}, \mathrm{P}, \mathrm{Si}, \mathrm{Fe})$ are simulated within the full ocean, 3-D context with no restoring to observations.

The BEC model roughly reproduces basin-scale patterns of macronutrient distributions, calcification, biogenic silica production, nitrogen fixation, primary and export production (Moore et al., 2002b, 2004). The model has recently been applied to quantify ocean biogeochemical sensitivity to variations in mineral dust deposition (iron inputs) (Moore et al., 2006), the feedbacks between denitrification and nitrogen fixation (Moore and Doney, 2007), and the ocean biogeochemical response to atmospheric deposition of inorganic nitrogen (Krishnamurthy et al., 2007). The results here are from the last year of a 3000-year simulation. This is an extension of the 2000-year control simulation described by Moore and Doney (2007). Iron cycling in the BEC model is discussed below. For further details on the BEC model, see Moore et al. (2002a, 2004) and Moore and Doney (2007). Moore et al. (2006) suggested some minor modifications to the original parameter values for the BEC model. Similar values are used here, as listed in Table S1 of Moore and Doney (2007).

Dissolved iron sources to the ocean in the BEC model include dissolution of iron from mineral dust particles deposited from the atmosphere and diffusion from shallower sediments, while a fraction of the scavenged iron is assumed to be lost to the sediments to balance these sources (Moore et al., 2004). There is one "dissolved" iron pool that is assumed to be bioavailable, with no distinction between soluble and colloidal forms. A constant fraction of the iron in 
mineral dust (here 2\%) dissolves instantaneously at the surface ocean, with some further iron release through a slower dissolution/disaggregation in the water column (Moore et al., 2004). Dust deposition is from the climatology of Luo et al. (2003). The sedimentary Fe source is crudely incorporated as a constant flux of $2 \mu \mathrm{mol} \mathrm{Fe} \mathrm{m}{ }^{-2}$ day $^{-1}$ from sediments at the bottom of the ocean grid whenever depth is less than $1100 \mathrm{~m}$ (Moore et al., 2004). As noted by Moore et al. (2004) the coarse resolution ocean grid only weakly captures the bathymetry of the continental shelves. Thus in many shelf regions the bottom level of the ocean grid is much deeper than the actual depth in shelf regions, providing little iron to surface waters.

Iron is removed from the dissolved pool through biological uptake by the phytoplankton and by particle scavenging. A fraction of the scavenged iron is added to the sinking particulate pool and will remineralize deeper in the ocean, while the remainder is assumed lost to the sediments. Iron scavenging is parameterized in the BEC model, based on the mass of sinking particles and the ambient dissolved iron concentration, to crudely account for the presumed influences of iron binding ligands on scavenging losses. Moore et al. (2004) described a scavenging rate that consisted of a base rate times the sinking particle flux divided by a reference particle flux. This approach can be described more simply by combining the base rate and reference flux constant coefficients into one base scavenging coefficient $\left(\mathrm{Fe}_{\mathrm{b}}\right)$ that is modified by the sinking particle flux (previously standing stock of POC was also included by Moore et al. (2004)). The parameterizations of iron scavenging from Moore et al. (2004) are outlined below. The base scavenging coefficient $\left(\mathrm{Fe}_{\mathrm{b}}=0.01369 \mathrm{ng}^{-1} \mathrm{~cm}^{-1}\right)$ is multiplied by the sinking particle flux to determine the base scavenging rate $\left(\mathrm{Sc}_{\mathrm{b}}\right)$. It is thus a net adsorption rate to sinking particles, similar to the simplest Th scavenging models. The sinking POC flux and sinking particulate mineral dust fluxes were added to get the sinking particle flux $\left(\mathrm{ng} \mathrm{cm}^{-2} \mathrm{day}^{-1}\right)$ available to scavenge iron, and a maximum scavenging rate $\left(\mathrm{Sc}_{b}=0.05476 \mathrm{day}^{-1}\right)$ was imposed (Eq. 1). Given the mean sinking fluxes in the model, the base scavenging rates including the particle effect at depths of $103 \mathrm{~m}, 502 \mathrm{~m}$, and $2098 \mathrm{~m}$ would be $7.5 \times 10^{-4}$ day $^{-1}, 1.6 \times 10^{-4}$ day $^{-1}$, and $8.1 \times 10^{-5}$ day $^{-1}$, respectively. These rates were further modified by the ambient iron concentrations. The total sinking flux is dominated by POC in surface waters, but due to shorter remineralization length scales for POC, the sinking dust flux becomes more important in the deep ocean. POC accounts for $93 \%, 67 \%$, and $38 \%$ of the sinking mass flux (POC + dust) at depths of $103 \mathrm{~m}, 502 \mathrm{~m}$, and $2098 \mathrm{~m}$, respectively.

$\mathrm{Sc}_{\mathrm{b}}=\mathrm{Fe}_{\mathrm{b}} *(\mathrm{sPOC}+\mathrm{sDust})$

$\mathrm{Sc}=\mathrm{Sc}_{\mathrm{b}}+(\mathrm{dFe}-0.6) *$ Chigh,$\quad($ where $\mathrm{dFe}>0.6 \mathrm{nM})$

$\mathrm{Sc}=\mathrm{Sc}_{\mathrm{b}} *(\mathrm{dFe} / 0.5), \quad($ where $\mathrm{dFe}<0.5 \mathrm{nM})$
Scavenged $\mathrm{Fe}=\mathrm{dFe} * \mathrm{Sc}$

The scavenging rate increases rapidly at higher iron concentrations (if dFe exceeds $0.6 \mathrm{nM}$, Chigh $=0.00904$, Eq. 2) when iron is assumed to begin exceeding the concentrations of strong binding ligands, and progressively decreases at low iron concentrations $(<0.5 \mathrm{nM}$, Eq. 3) to reflect protection from scavenging losses due to strong iron binding ligands. The scavenging rate is multiplied by the ambient dissolved iron concentration to get the amount removed by scavenging (Eq. 4), of which $10 \%$ is put into the sinking particulate pool and $90 \%$ of scavenged iron presumed lost to the sediments. Some ocean biogeochemical models assume that all scavenged iron is lost from the system (Archer and Johnson, 1999; Christian et al., 2002; Aumont et al., 2003; Parekh et al., 2004, 2005). Gregg et al. (2003) and Aumont and Bopp (2006) add all scavenged iron to the sinking pool to remineralize at depth. Doney et al. (2006) send $60 \%$ to the sinking particulate pool.

\subsection{Improving the BEC iron cycle parameterizations}

We will show that the model tends to overestimate surfaceiron concentrations in the standard configuration. In part to address this deficiency, we lowered the half-saturation constants for iron uptake to values of $0.04 \mathrm{nM}$ for the small phytoplankton, $0.06 \mathrm{nM}$ for the diazotrophs, and $0.09 \mathrm{nM}$ for the diatoms. These values are within the ranges reported in the literature. A half-saturation constant of $0.035 \mathrm{nM}$ was estimated for community uptake in the tropical Pacific (Price et al., 1994). The rates for large diatoms are often substantially higher than our assumed value $(>0.2 \mathrm{nM}$, Timmermans et al., 2004; de Baar et al., 2005) but lower rates have been observed for smaller diatoms from HNLC regions $(0.12 \mathrm{nM}$ for the Iron Ex II diatom dominated bloom, Fitzwater et al., 1996; diatom values of $0.05-0.13 \mathrm{nM}$ for the Ross Sea, Coale et al., 2003). Kudo et al. (2006) estimated values of $0.10 \mathrm{nM}$ and $0.08 \mathrm{nM}$ for the micro- and nano-sized phytoplankton fractions in the SERIES experiment in the NW subarctic Pacific.

We also modified some of the basic assumptions of the iron scavenging parameterizations of Moore et al. (2004). Often, ocean biogeochemical models assume that $100 \%$ of the dissolved iron scavenged onto particles is lost to the sediments (Moore et al., 2002; Christian et al., 2002; Aumont et al., 2003; Parekh et al., 2005). This is unrealistic as most of the particles that scavenge Fe in the upper water column will not reach the ocean floor, but will remineralize in the upper ocean, releasing the iron. Moore et al. (2004) put 10\% of the scavenged iron into sinking particulates, which were remineralized within the water column. Here we increase this fraction to $90 \%$ (similar to Aumont and Bopp (2006) where all scavenged iron is added to the sinking particulate pool). The remaining $10 \%$ is assumed to be lost to the sediments and provides the ocean sink necessary to balance inputs from 
the atmosphere and the sediments (our model does not include a sedimentary diagenesis component). This more realistic treatment of scavenged iron allows signals from dust deposition and margin sedimentary iron to penetrate deeper into the ocean as iron is scavenged, released, then scavenged again deeper in the water column.

We also increased the fraction of sinking dust particles that reach the ocean floor from $85 \%$ to $92 \%$ over a $4000-\mathrm{m}$ water column. The remineralization length scale for the "hard" dust fraction (97\% of the dust that enters the ocean as sinking particulates) is increased from $40000 \mathrm{~m}$ to $120000 \mathrm{~m}$. Thus, only about $3 \%$ would dissolve over a 4000-m water column (see Armstrong et al., 2002 and Moore et al., 2004 for details of the particle remineralization scheme). The remaining $3 \%$ that enters the ocean as sinking particulates is remineralized in the upper water column with a length scale of $600 \mathrm{~m}$. As with the Old BEC model, two percent of the dust flux is assumed to dissolve instantaneously upon deposition to the surface ocean. Biogeochemical models typically include only this surface dissolved iron input flux, though Aumont and Bopp (2006) also include subsurface dissolution of dust. It seems likely that some slow additional dissolution of iron occurs as dust particles sink through the water column, particularly within low $\mathrm{pH}$ microenvironments in aggregates or zooplankton guts, and through biological "stripping" of iron from particles as suggested by the recent FeCYCLE field experiment results (Frew et al., 2006). Our model specification where $3 \%$ of the particulate iron in dust dissolves in the upper water column is meant to reflect that these biological processes are weighted more towards the surface ocean following the general distributions of organic material and zooplankton biomass.

Moore et al. (2004) scaled iron scavenging by the sinking particle flux of particulate organic carbon (POC) plus mineral dust. We modified this definition of sinking particle mass flux in conjunction with a first-order scavenging coefficient $\left(\mathrm{Fe}_{\mathrm{b}}=0.00384\left(\mathrm{ng}^{-1} \mathrm{~cm}^{-1}\right)\right.$, where the sinking mass $=\mathrm{POC}$ $* 6+$ biogenic silica $(\mathrm{bSi})+\mathrm{CaCO}_{3}+$ mineral dust (all in units of $\mathrm{ng} \mathrm{cm}^{-2} \mathrm{day}^{-1}$ ). Here we do not impose a maximum scavenging rate, unlike in Moore et al. (2004). The sinking mass flux in the deep ocean is dominated by the mineral ballast components (bSi, $\mathrm{CaCO}_{3}$, and lithogenic, Armstrong et al., 2002; Klaas and Archer, 2002). Thus this formulation allows the model to more accurately capture the sinking flux available to scavenge iron in the deep ocean. Sinking flux in the upper ocean is dominated by particulate organic matter (POM), which decreases more rapidly with depth due to a shorter remineralization length scale. The POC flux is multiplied by a factor of 6 to reflect the non-carbon portions of organic matter, and to reflect an increased scavenging efficiency in the upper ocean due to higher particle concentrations, "stickier" freshly produced organic material, and more colloidal organic material (COM), which is thought to be important in trace metal scavenging. All three factors are likely to scale to the first order with POC flux and biological ac- tivity. Recent studies point to a strong influence of COM on the scavenging and removal of ${ }^{234} \mathrm{Th}$ from upper ocean waters, and perhaps even throughout the water column, in the form of organic coatings on the mineral substances sinking through the water column (Guo et al., 2002; Passow et al., 2006; see review by Santschi et al., 2006). Similar processes probably influence the scavenging and removal of iron. In the real ocean, the specific organic coatings and particle size distributions strongly influence trace metal scavenging (i.e. Burd et al., 2000; Savoye et al., 2006). These factors are not simulated explicitly in the BEC model, but are parameterized as a net scavenging onto the sinking particles. Thus, our approach is similar to the simplest models of thorium scavenging (see review by Savoye et al., 2006) except that we include an explicit desorption of iron from the sinking particles (see below).

We also increase scavenging rate rapidly when dissolved iron concentrations exceed $0.6 \mathrm{nM}$, implicitly including the ligand effect as in Moore et al. (2004). Thus, we assume that almost all of the iron at concentrations less than $0.6 \mathrm{nM}$ will be bound to organic ligands and have reduced scavenging loss rates. Unlike in Moore et al. (2004), scavenging rates are not progressively reduced as ambient iron falls to lower concentrations. Also, new in this work is a desorption release of dissolved iron from sinking particles, based on a firstorder rate constant as suggested for Th (Bacon and Anderson, 1982) and applied to iron by Parekh et al. (2004). Because sinking particles are implicit in the model and once formed are assumed to sink and remineralize instantly through the water column at the same location (Moore et al., 2004), this rate is not expressed in units of time, but rather length $\left(6.0 \times 10^{-6} \mathrm{~cm}^{-1}\right)$. This can be converted to the more familiar time units if we assume some mean sinking speed (at $100 \mathrm{~m}^{-1}$ day the desorption rate would be 0.06 day $^{-1}$ ). Parekh et al. (2004) made sensitivity tests with desorption rates between 0.055 and 0.27 day $^{-1}$ ). Desorption is only applied to the particulate Fe sinking pool coming from particle scavenging and biological uptake and export, not to the inert $\mathrm{Fe}$ in the non-dissolving portion of mineral dust particles.

There are large uncertainties in the relative importance of desorption to the cycling of both $\mathrm{Th}$ and $\mathrm{Fe}$ (Quigley et al., 2001; Parekh et al., 2004; Santschi et al., 2006). Quigley et al. (2001) found Th sorption to natural organic matter to be irreversible over a 5-day period and suggested that there is negligible desorption given the short lifetime of ${ }^{234} \mathrm{Th}$. Although little is known about possible desorption of iron from particles, even a slow release might be substantial for slower sinking particles in the oceans. We conduct two sensitivity simulations to examine the impacts of including desorption on iron distributions: one simulation with no desorption release and another simulation with desorption release reduced by half.

We also modify the sedimentary source for iron in the model. We use a sedimentary source that is weighted by the actual ocean bathymetry from the ETOPO2 version 2.0, 


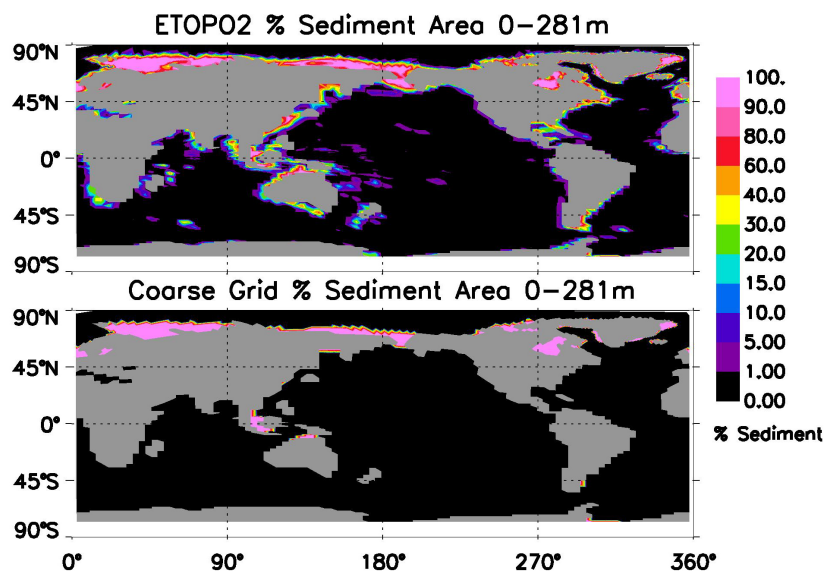

Fig. 2. The percentage of grid cell area that would consist of ocean sediments (integrated over the upper $281 \mathrm{~m}$ ) in the ETOP2V2 database, which is used in estimating the sedimentary source of dissolved iron (A). Also, shown are the areas with depths less than 281 $\mathrm{m}$ on the coarse resolution ocean grid $(\mathbf{B})$.

2-min global gridded database (US Dept. of Commerce, 2006), following the approach of Aumont and Bopp (see supplementary material, 2006: http://www.biogeosciences.net/ 5/631/2008/bg-5-631-2008-supplement.zip). Thus, for each cell in the model, we calculate what fraction of the cell area that would consist of sediments based on the high resolution ETOPO2V2 database (what portion of the ocean floor in ETOPO2V2 had depths that lie within that grid box). This decouples the sediment source from the physical ocean grid, and provides for a more realistic distribution of the sedimentary iron source. Figure 2 shows the percentage area with sedimentary flux integrated through the upper $281 \mathrm{~m}$ from the old scheme (100\%, only in bottom ocean grid cell) compared with the new sedimentary source based on the ETOPO2V2 dataset. The influence of the continental shelves are much better accounted for in many areas where they previously had no influence on sedimentary iron flux in the upper ocean. In addition, important iron sources surrounding islands in the open ocean are represented, such as the shallow waters associated with the Kerguelen Plateau and Kerguelen Islands $\left(70^{\circ} \mathrm{E}, 50^{\circ} \mathrm{S}\right.$, Moore and Abbott, 2000; Blain et al., 2001).

We also employ a more sophisticated estimate of the $\mathrm{Fe}$ flux from sediments than the constant value used previously. Elrod et al. (2004) found a strong correlation between iron release from sediments and organic carbon oxidation in the sediments $\left(0.68 \mu \mathrm{mol} \mathrm{Fe} \mathrm{mmol} \mathrm{Cox}-1 \mathrm{~m}^{-2} \mathrm{day}^{-1}\right)$ using benthic flux chamber data off the North American west coast from Berelson et al. $(1996,2003)$. We simplify this relation using $0.68 \mu \mathrm{mol} \mathrm{Fe} \mathrm{m}{ }^{-2} \mathrm{day}^{-1}$ release for each mmol of $\mathrm{C} \mathrm{m}^{-2}$ day $^{-1}$ sinking into the ocean grid cell where sedimentary flux is being calculated. The iron flux is then weighted by the fraction of bottom area of the ETOPOV2 data that falls within the bounds of each model grid cell (as in Aumont and
Bopp, 2006). The sedimentary iron flux was determined by the sinking $\mathrm{C}$ fluxes from year 3000 of the Old BEC simulation (see below), and held constant through all simulations. There is no explicit depth dependence for the model's sedimentary iron source. It is a function of only the sinking POC fluxes. Thus there are much higher iron fluxes beneath productive continental margins, and even in the deep ocean there is a small source. Elrod et al. (2004) noted a delay of several months between organic matter sinking flux and iron release from the sediments. We simplify by assuming a constant flux based on the annual sinking POC flux. In some regions the resulting Fe sediment flux grid was modified to correct mismatches between the ETOPO2V2 and CCSM3 grids, and to better match local bathymetry maps and dissolved-iron measurements (Mackey et al., 2002; Reddy and Arrigo, 2006; Bruland et al., 2005). Aumont and Bopp (2006) also employed a variable Fe flux from the sediments, with a maximum flux set at $1 \mu \mathrm{mol} \mathrm{Fe} \mathrm{m}{ }^{-2}$ day $^{-1}$.

Beyond the assumptions and modifications to the model outlined above, we also adjusted by trial and error the other parameters in the BEC iron cycle to better match the dissolved-iron concentrations from our observational database by minimizing the root mean square difference of the log-transformed model output and observational values. The first-order scavenging rate $\left(\mathrm{Fe}_{\mathrm{b}}=0.00384 \mathrm{ng}^{-1} \mathrm{~cm}^{-1}\right)$ was adjusted by model-data comparisons with both euphotic zone $(0-103 \mathrm{~m})$ and subsurface observations of dissolved iron $(103-502 \mathrm{~m})$. The subsurface observations are preferable for this parameter tuning as they are less affected by the uncertainties associated with surface inputs and biological uptake of dissolved iron. However, there are far more observations in surface waters than in subsurface waters. The optimal value for $\mathrm{Fe}_{\mathrm{b}}$ was similar for euphotic zone and subsurface waters $(\sim 6 \%$ higher for subsurface waters), implying a similar dependency on sinking particle flux. This was not the case for the unitless, scaling coefficient (Chigh) used in the equation that increased particle scavenging at high iron concentrations. The optimal value for surface waters was a factor of 3-4 higher than in subsurface waters. For our new optimized parameter set, we use an intermediate value (Chigh $=0.00904)$ that gave similar rms model-data differences in surface and subsurface waters for high-end iron concentrations (where both model and observation exceeded $0.6 \mathrm{nM})$. The new scavenging parameterization is given by $\mathrm{Fe}_{\mathrm{b}}$ times the sinking mass flux (Eq. 5, this replaces Eq. 1), and it is increased under high iron conditions (above $0.6 \mathrm{nM}$, Eq. 2). The scavenged iron (Eq. 4) is removed from the dissolved pool, and $90 \%$ is put into the sinking particulate iron pool (10\% is presumed to be buried in the sediments).

$\mathrm{Sc}_{\mathrm{b}}=\mathrm{Fe}_{\mathrm{b}} *\left(\mathrm{sPOC} * 6+\mathrm{sDust}+\mathrm{sbSi}+\mathrm{sCaCO}_{3}\right)$

\subsection{Experiments with the BEC model}

We compare BEC model results with the modifications outlined above, optimized for a better fit to the observational 
dataset (New BEC), to the last year from an earlier 3000-year equilibrium "Control" simulation from by Moore and Doney (2007), here referred to as Old BEC. The New BEC simulation was 201 years, long enough for the iron cycle to spin up with reasonably small drifts (average of $0.022 \%$ per decade drift in global mean iron concentration over the last 20 years, $0.0025 \%$ per decade in the upper $502 \mathrm{~m}$ ). We focus on model output from year 201. To gauge the sensitivity to iron sources we compare with two additional 201-year simulations: one with only dust inputs of dissolved iron (DustOnly) and one with only sedimentary inputs of dissolved iron (SedOnly). We also made three other sensitivity simulations: 1) LowFea low-end estimate of iron inputs, with a $1 \%$ surface dissolution of the iron in mineral dust as the only source; 2) NoDesorp - does not include Fe desorption from sinking particles; and 3) LowDesorp - desorption rate is decreased by $50 \%$ to $3.0 \times 10^{-6} \mathrm{~cm}^{-1}$. In the LowFe simulation, particle scavenging of iron occurs only where iron concentration exceeds $0.6 \mathrm{nM}$. Except for these noted differences, all the sensitivity simulations are identical to the New BEC simulation.

To evaluate the simulations against the observational database and tune model parameters, we log transformed the observations and model output and then computed the correlation coefficient $(r)$ and the root mean square (rms) difference. Log transformation provides for a more equal weighting of model-data differences across the relatively wide range of iron concentrations (rather than weigh high-end values much more strongly than low iron values without log transformation). For comparison, we also present statistics on the raw, non-log transformed data.

\section{Results}

\subsection{Observed iron distributions in the oceans}

The observational dataset is heavily weighted towards the upper ocean with $66 \%$ of observations from depths less than $103 \mathrm{~m}$, and $86 \%$ from depths less than $502 \mathrm{~m}$. The dataset is also weighted strongly towards the Northern Hemisphere (75\% of the data). The Southern Hemisphere data is mainly from the Southern Ocean (65\% of S.H. data), which we define as latitudes greater than $40.5^{\circ} \mathrm{S}$, with few observations in the lower latitudes, mainly in the South Atlantic (18\%). There are also strong seasonal biases with only $3.3 \%$ of samples collected during winter months, mainly at low latitudes. Away from the high dust deposition regions, particularly at higher latitudes, one would expect a winter maximum in surface iron concentrations due to deep mixing and weakened biological uptake, and the generally increasing concentrations of iron with depth. This is the pattern seen in our model output at higher latitudes, but observational data is not available to evaluate this seasonal cycle. Spring months had the most observations (46\%) followed by summer (30\%) and fall (21\%). Dust deposition typically has a strong seasonal com-

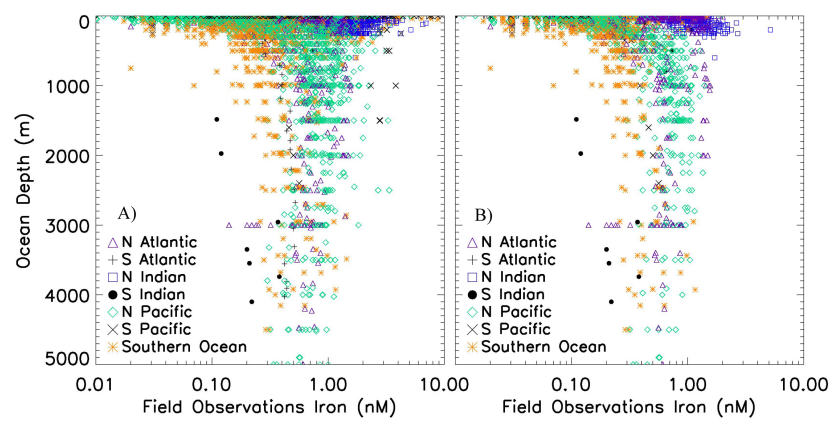

Fig. 3. All observations of dissolved iron plotted as a function of depth with symbols denoting ocean basins (A); observations from the "open ocean" subset (see text for details) plotted as a function of depth with symbols denoting ocean basin (B).

ponent peaking during spring or summer months. Thus, iron can have a stronger seasonality, even at low latitudes, than typically seen in oceanographic data. Time series observations that captured the full seasonal cycle $(\sim$ monthly sampling) over multiple years would be an immensely helpful addition to the available observations. No such datasets currently exist to our knowledge. Only a few studies have examined iron concentration changes over more than one season (Measures and Vink, 2001, Sedwick et al., 2005; Boyle et al., 2005).

Vertical profiles of dissolved iron tend to follow two patterns: 1) a surface minimum due to surface depletion by biological uptake and scavenging processes; or 2) a surface maximum where there is strong influence by dust deposition events (Johnson et al., 1997a, 2003; de Baar and de Jong, 2001). All observations of dissolved iron are plotted against ocean depth in Fig. 3a, with a similar plot for the open-ocean data in Fig. 3b. There are some obvious, strong regional patterns in the iron distributions. The highest surface water concentrations are typically seen in the high dust deposition regions of the North Indian Ocean and the North Atlantic basins (hereafter referred to as the "high deposition regions"), while the lowest surface values are mainly in the Southern and Pacific oceans (Fig. 3). Low surface concentrations are $(<0.1 \mathrm{nM})$ are also seen in some South Atlantic observations. The highest surface concentrations are from coastal waters (with a few points exceeding $10 \mathrm{nM}$ ) off of Peru (Bruland et al., 2005) and in the Southern Ocean near the Kerguelen Islands (Blain et al., 2001; Bucciarelli et al., 2001). There is considerable variation in iron concentrations within individual basins, which reflects differential inputs and removal rates.

In the open-ocean dataset, the mean surface-iron concentration $(\leq 20 \mathrm{~m})$ for all areas except the high-deposition regions is $0.25 \pm 0.23 \mathrm{nM}( \pm 1 \sigma)$, and the mean in the highdeposition regions is $0.76 \pm 0.27 \mathrm{nM}$ (recall the North Atlantic and North Indian basins are our high deposition regions). Areas outside of the high-deposition regions can 


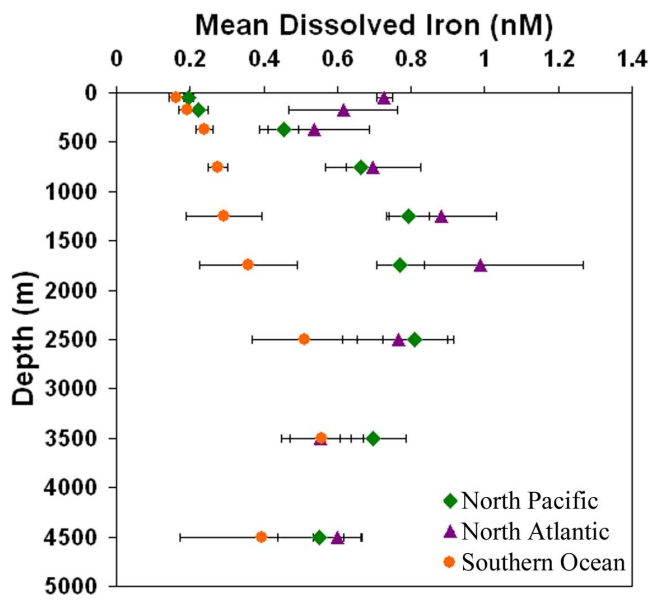

Fig. 4. Mean profiles of dissolved iron in the North Atlantic, North Pacific, and Southern Ocean averaged over the depth intervals: 0$100 \mathrm{~m}, 100-250 \mathrm{~m}, 250-500 \mathrm{~m}, 500-1000 \mathrm{~m}, 1000-1500 \mathrm{~m}, 1500$ $2000 \mathrm{~m}, 2000-3000 \mathrm{~m}, 3000-4000 \mathrm{~m}, 4000-5000 \mathrm{~m}$.

be further subdivided between HNLC zones (where annual SeaWiFS chlorophyll is $<0.5 \mathrm{mg} / \mathrm{m}^{3}$ and surface nitrate concentrations exceed $4.0 \mu \mathrm{M}$ in the World Ocean Atlas 2001, Conkright et al., 2001) and the non-HNLC regions. The mean concentration for the HNLC regions is $0.15 \pm 0.16 \mathrm{nM}$ and for the non-HNLC regions the mean is $0.27 \pm 0.23 \mathrm{nM}$. The iron-limited HNLC regions have mean surface concentrations of dissolved iron that are only moderately lower than in the non-HNLC areas, with both means considerably higher than the mean surface value of $0.07 \mathrm{nM}$ calculated by Johnson et al. (1997a). These higher values reflect three factors: 1) additional sampling of surface waters shortly after dust deposition events, which in the North Pacific for example can raise surface water concentrations from background levels of $<0.2 \mathrm{nM}$ to values in excess of $0.6 \mathrm{nM}$ (Bruland et al., 1994; Wu et al., 2001; Johnson et al., 2003); 2) increased high latitude sampling early and late in the growing season when deeper mixing might increase iron concentrations; and 3) possibly systematic differences between groups measuring iron. The mean surface iron concentration for the equatorial Pacific $\left(10^{\circ} \mathrm{S}\right.$ to $\left.10^{\circ} \mathrm{N}\right)$ was $0.077 \pm 0.033 \mathrm{nM}$, close to the Johnson et al. (1997a) value.

Many of the elevated deep-water concentrations are associated with continental margins and do not appear in our open-ocean subset (compare Fig. 3a and b) most notably in the Pacific data. Deep-water values in the open-ocean dataset range mainly between $\sim 0.2-1.0 \mathrm{nM}$, with the Southern Ocean has consistently low values and the North Atlantic and North Pacific have higher, similar concentrations. There is sufficient data in the North Atlantic, North Pacific, and Southern Ocean to calculate mean profiles of dissolved iron from the open ocean dataset (Fig. 4, error bars show 95\% confidence interval). In the upper ocean, mean dissolved iron concentrations were quite low in the Southern Ocean

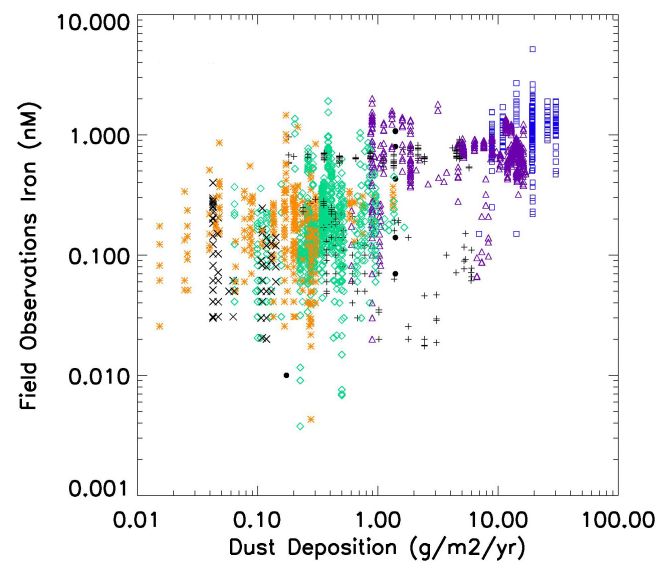

Fig. 5. All observations of dissolved iron $(<300 \mathrm{~m})$ from the open ocean plotted against atmospheric transport model estimates of annual mineral dust deposition in the climatology of Luo et al. (2003). Symbols indicate ocean basin as in Fig. 3.

$(0.16 \mathrm{nM}$ upper $100 \mathrm{~m})$ and in the North Pacific $(0.20 \mathrm{nM}$ upper $100 \mathrm{~m}$ ), with much higher iron levels in the North Atlantic $(0.73 \mathrm{nM})$. There is a subsurface minimum in the North Atlantic between 100-250 m depth, noted previously (Wu et al., 2001; Wu and Boyle, 2001; Sedwick et al., 2005; Bergquist and Boyle, 2006). Below $250 \mathrm{~m}$ the profiles for the North Atlantic and North Pacific basins are similar, despite a difference of roughly two orders of magnitude in dust deposition (Figs. 4 and 5). This similarity was noted previously in a much smaller dataset by Johnson et al. (1997a). The Southern Ocean has much lower mean concentrations below $250 \mathrm{~m}$ with the largest difference between $1000-1500 \mathrm{~m}$ by a factor of $\sim 2.6-2.9$. Values appear to converge somewhat in the deepest ocean, but there were few observations below $2000 \mathrm{~m}$ (see Fig. 3b). We calculated mean iron concentrations below $500 \mathrm{~m}$ depth for these basins as $0.37 \pm 0.19$ $(n=96)$ for the Southern Ocean, $0.74 \pm 0.33 \mathrm{nM}(n=107)$ for the North Atlantic, and $0.74 \pm 0.21 \mathrm{nM}(n=232)$ for the North Pacific. The North Pacific data may reflect a strong influence from continental sources (see discussion below, Fig. 1). If all observations are included (rather than just the open ocean subset) mean concentrations are actually higher in the North Pacific $(0.87 \pm 0.37 \mathrm{nM}, n=468)$ than in the North Atlantic $(0.76 \pm 0.31 \mathrm{nM}, n=149$, difference significant at $95 \%$ C.I.), reflecting in part more sampling near the continents in the North Pacific. The Southern Ocean mean for all data was $0.46 \pm 0.28 \mathrm{nM}(n=160)$. It is remarkable that the mean profile for the North Pacific is statistically indistinguishable from the Southern Ocean in the upper $250 \mathrm{~m}$, and indistinguishable from the North Atlantic below this depth range (Fig. 4).

There is a clear signal from dust deposition in the depthresolved iron data with the highest concentrations in the open-ocean dataset all in the high-deposition regions, and 
with the lowest upper-ocean iron concentrations in the low deposition areas of the Southern Ocean and the equatorial Pacific (Figs. 3-4). In Fig. 5, we plot all upper ocean $(<300 \mathrm{~m})$ dissolved-iron observations from the open-ocean dataset against the climatological annual dust deposition estimated by Luo et al. (2003) for the late 20th century. There is considerable uncertainty in these model estimates of dust deposition, but some general patterns seem fairly robust. Dust deposition varies over three orders of magnitude while most of the iron observations fall within a narrower range ( $\sim$ two orders of magnitude). This reflects the non-linear nature of iron removal processes, although variations in aerosol iron solubility may also play a role, as the lower deposition areas generally farther from source regions may have higher solubilities (see Mahowald et al., 2005 and references therein). The regions beneath the major dust plumes in the North Atlantic and northern Indian oceans receive two orders of magnitude higher dust deposition than most other areas. The North Pacific receives $\sim 2-5$ times more dust than most Southern Ocean sites, although some of the very lowest deposition rates are in the equatorial Pacific. There is some overlap across all the regions, some North Atlantic sites receive low dust levels, and the South Atlantic sites span the range from low to high deposition. A few Southern Ocean regions receive more than $1 \mathrm{~g}$ dust $\mathrm{m}^{-2} \mathrm{yr}^{-1}$ (Fig. 5).

The correlation between estimated dust deposition and observed dissolved iron concentration is relatively weak $(r=0.7)$ despite the often assumed dominant role for dust deposition as an iron source for the open ocean. In fact, if the high dust inputs are excluded (dust deposition $>1.0 \mathrm{~g} \mathrm{~m}^{-2} \mathrm{yr}$ ) there is no correlation between dust inputs and observed-iron concentrations $\left(r^{2}=0.096\right)$. For each estimated dust-deposition rate, there is typically a wide range of observed iron concentrations. The relatively weak correlation is due to variable removal by biological uptake and particle scavenging, the influence of other Fe sources, and errors in the dust deposition estimates. The biological removal of iron in surface waters depends on a number of factors that will vary by region, such as the depth of the mixed layer and potential light limitation, the concentrations of other key nutrients, and their influence on productivity. These same factors will influence the surface and sub-euphotic zone scavenging of iron as the biology is the main source of scavenging particles in the upper ocean.

A number of factors will tend to deplete iron to low levels in surface waters over a range of low-to-medium iron input levels. Production of the colloids which bind with iron, which leads to aggregation and scavenging removal probably peaks in the euphotic zone. Particle concentrations, which scavenge iron, are also probably highest in the lower euphotic zone. Biological uptake will also remove substantial amounts of dissolved iron, particularly as some larger phytoplankton engage in luxury uptake of iron. At very low iron input levels, or as these processes deplete iron down to very low levels $(<0.1-0.15 \mathrm{nM})$, the loss rate for dissolved iron

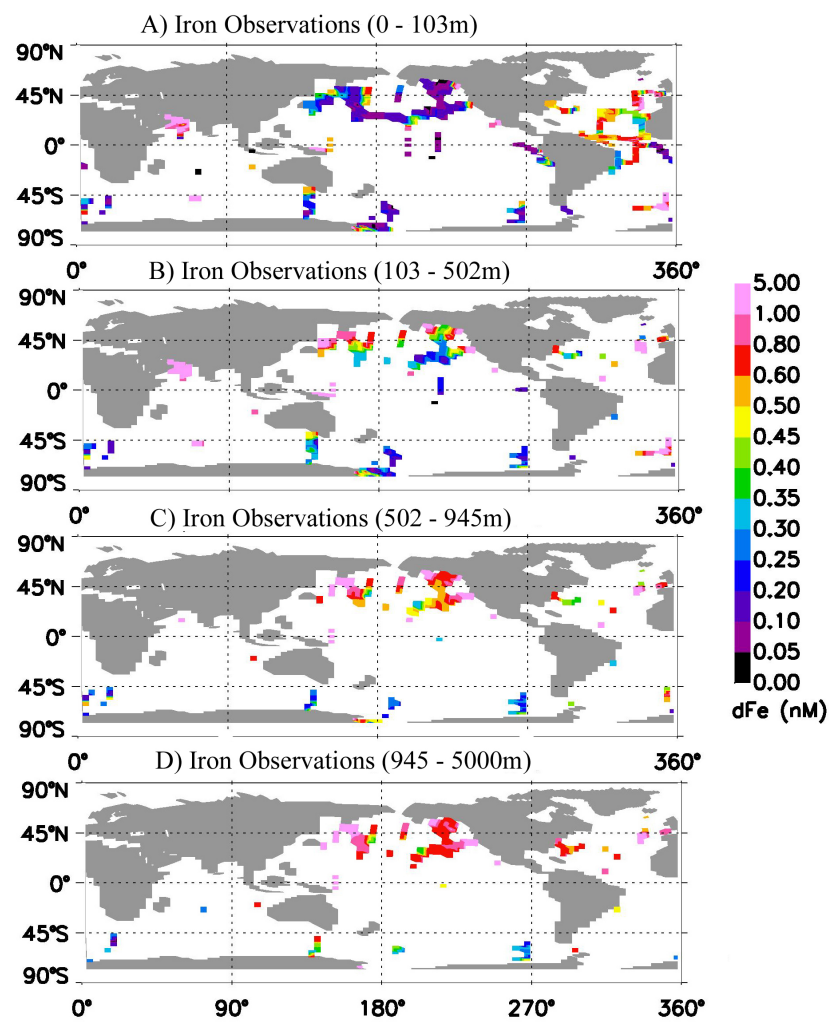

Fig. 6. Iron observations averaged onto CCSM3 ocean grid over depth ranges from 0-103 $\mathrm{m}$ (A), 102-502 $\mathrm{m}$ (B), 502-945 m (C), and from 945-5000 $\mathrm{m}$ (D).

will decline. A higher proportion of the ligand-bound iron may exist in the soluble size class (Nishioka et al., 2001, 2005) and, therefore, will not be subject to substantial removal by aggregation and scavenging. Also, the phytoplankton uptake will decrease as available iron approaches the half-saturation values for iron uptake and phytoplankton become increasingly iron stressed (growing more slowly and decreasing their cellular $\mathrm{Fe} / \mathrm{C}$ ratios). Thus, outside the highest iron input areas, dissolved iron concentrations will tend to be depleted to low levels in surface waters $(<0.2 \mathrm{nM})$, despite a fairly wide range of iron inputs from mineral dust and other sources. Therefore, surface iron concentrations are a poor proxy for iron input rates.

It is also notable that observed-iron concentrations do not increase much beyond $\sim 1-2 \mathrm{nM}$ even as dust inputs increase from $\sim 1$ to $30 \mathrm{~g} \mathrm{~m}^{-2} \mathrm{yr}^{-1}$ (Fig. 5). This strongly suggests that there is an upper bound on open-ocean iron concentrations, which is set by elevated scavenging losses as iron reaches these high concentrations. Johnson et al. (1997a) suggested that scavenging losses increased as iron exceeded $\sim 0.6 \mathrm{nM}$. Some such threshold does appear valid in the current observational database, but probably varies between regions as a function of the concentration of the strong iron-binding ligands, ranging perhaps between $\sim 0.5-1.5 \mathrm{nM}$. 


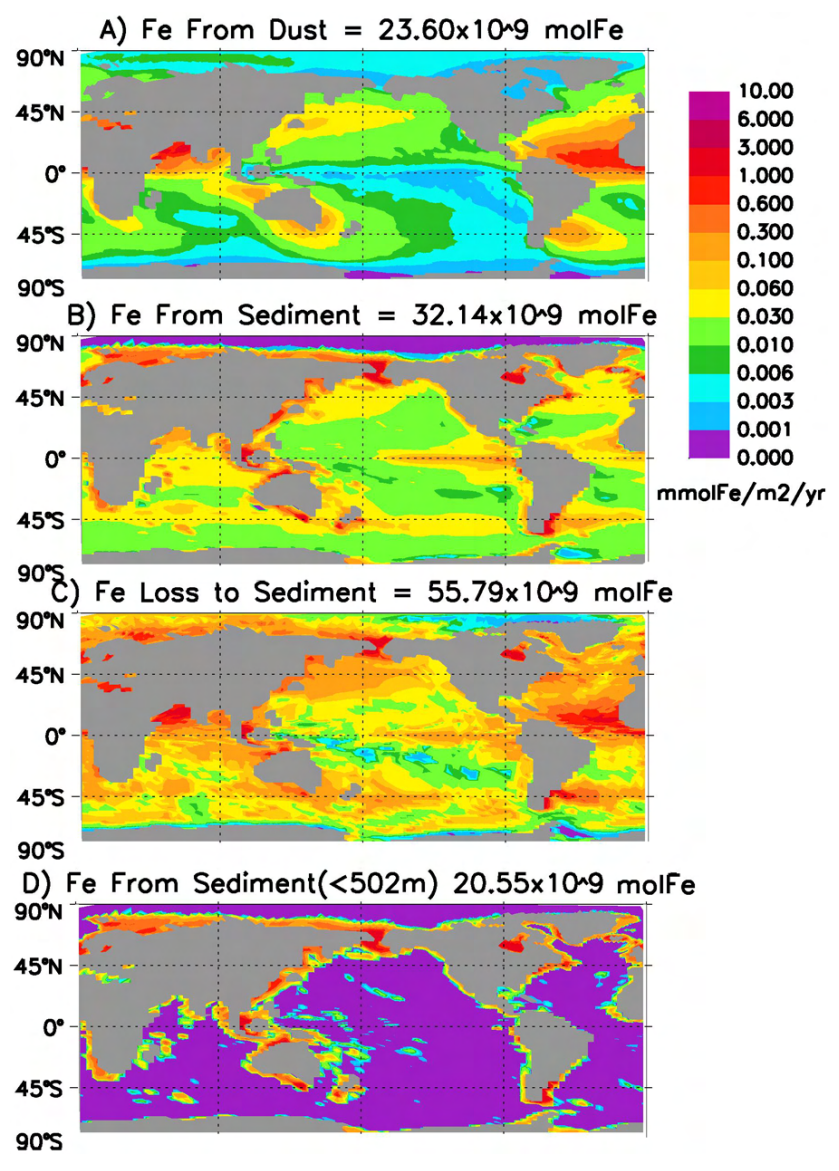

Fig. 7. Water column integrated input of dissolved iron from mineral dust (A) and from the sediments (B), the loss of scavenged iron to the sediments $(\mathbf{C})$, and the sedimentary source of dissolved iron in the upper $502 \mathrm{~m}$ (D).

Dissolved iron concentrations are consistently below $0.6 \mathrm{nM}$ in the deep Southern Ocean and often above this value in other regions. Yet the range of iron concentrations in the deep ocean is narrow compared with the wide variations in dust deposition (Figs. 3, 4 and 5).

We compare spatial plots of all the iron observations averaged onto the BEC ocean model grid over different depth ranges in Fig. 6. This figure illustrates the sparseness of observational data in most ocean regions. The North Pacific is the best sampled ocean basin, followed by the North Atlantic. In surface waters $(0-103 \mathrm{~m})$ dissolved-iron concentrations are typically quite low $(<0.2 \mathrm{nM})$ away from the continental margins and the high dust deposition regions (Fig. 6a). Observed iron concentrations are higher near Hawaii than areas to the east and west. It is unclear what drives this pattern. One possibility is that increased sampling near Hawaii has enabled more iron measurements shortly after dust deposition events (Johnson et al., 2003; Boyle et al., 2005). There are some surprisingly low-iron concentrations near the strong source region in northern Africa. Elevated concentrations are seen near the continents, with decreasing values moving offshore in the Ross Sea, the North Pacific, South Pacific, and south of Australia (Fig. 6a). A similar pattern can be seen in the subsurface observations in the Ross Sea, the eastern North Atlantic, the eastern North Pacific, the gulf of Alaska extending southwards from land, and in the western North Pacific (Fig. 6b and c). In subsurface waters (103-502 m), the coastal source can often be seen to extend farther offshore than in surface waters, where removal rates are higher (Fig. 6). This pattern extends into the deep ocean as well (Figs. 1 and 6d) due to reduced particle flux and scavenging losses at depth. Essentially, wherever onshore-offshore transects have been taken, the influence of the continental margin source extends far offshore. In the North Pacific, where there are the greatest number of onshore-offshore transects, there is a consistent trend over all depth ranges with higher concentrations along the continental margins decreasing towards the center of the basin (Fig. 6). This pattern may be present in all ocean basins, away from the high dust-deposition regions in the northern Indian and tropical Atlantic oceans.

\subsection{Simulations of the marine iron cycle and associated biogeochemistry}

We next analyze our BEC model results in the context of the observational database. The total simulated dissolved iron input to the oceans from our improved sedimentary source $\left(3.2 \times 10^{10} \mathrm{~mol} \mathrm{Fe} \mathrm{yr}^{-1}\right)$ is similar in magnitude to that from

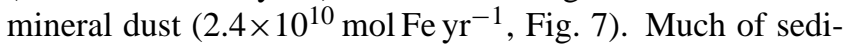
mentary source comes from the continental margins at relatively shallow depths $(64 \%<502 \mathrm{~m}$, compare Fig. $7 \mathrm{~b}$ and d). A similar fraction of the total release from mineral dust is in the upper ocean $(55 \%<502 \mathrm{~m})$. After 201 years, the combined dust and sediment sources are balanced by the $10 \%$ of scavenged iron that is lost to the sediments (Fig. 7). Comparing the spatial patterns seen in Fig. 7, it appears that much of the iron input into the high dust-deposition regions (in the North Atlantic and North Indian basins) and along the continental margins is scavenged locally before the circulation has time to advect it very far. Our estimate for sedimentary dissolved iron input is about one-third of the value of $8.9 \times 10^{10} \mathrm{~mol} \mathrm{Fe} \mathrm{yr}^{-1}$ of Elrod et al. (2004). The difference is likely due to our use of simulated organic carbon export (typically lower than observations on the continental shelves) to estimate the iron flux. Previous estimates for dissolved iron inputs from dust, typically only including a surface dissolution include $9.6 \times 10^{8}-9.6 \times 10^{9}{\mathrm{~mol} \mathrm{Fe} \mathrm{rr}^{-1}}^{-1}$ (Fung et al., 2000), $2.4 \times 10^{9} \mathrm{~mol} \mathrm{Fe} \mathrm{yr}^{-1}$ (Aumont et al., 2003), $3.8 \times 10^{10} \mathrm{~mol} \mathrm{Fe} \mathrm{yr}^{-1}$ (Moore et al., 2004), and $2.6 \times 10^{9} \mathrm{~mol} \mathrm{Fe} \mathrm{yr}^{-1}$ (Parekh et al., 2005). Recent estimates of surface input based on higher surface solubilities for iron in mineral dust range from $2.0 \times 10^{10}-8.9 \times 10^{10} \mathrm{~mol} \mathrm{Fe} \mathrm{yr}^{-1}$ by Luo et al. (2005) to $13 \times 10^{10} \mathrm{~mol} \mathrm{Fe} \mathrm{yr}^{-1}$ by Fan et al. (2006). 


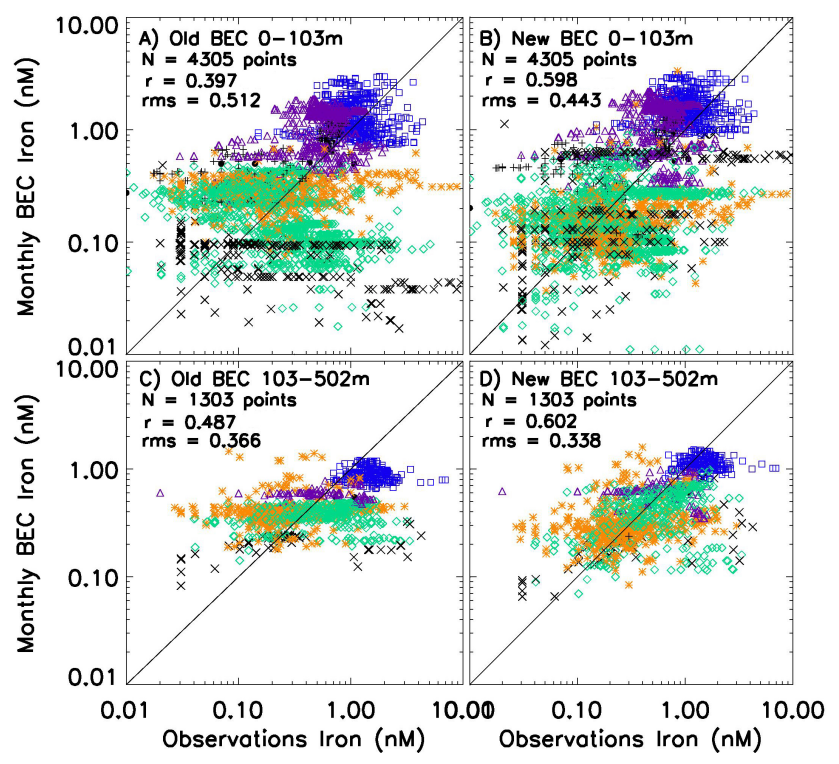

Fig. 8. Comparison of ocean measurements of dissolved iron with model output sub-sampled at the same month, location, and depth of the field observations for the Old BEC (left) and New BEC (right) simulations in surface waters $(0-103 \mathrm{~m}$, panels $(\mathbf{A})$ and $(\mathbf{B}))$ and in subsurface waters (103-502 m, panels (C) and (D)). Symbols indicate ocean basin as in Fig. 3.

We next compare the simulated iron concentrations and distributions from the Old and New BEC simulations in the context of the observational database. The observations from surface waters $(0-103 \mathrm{~m})$ and from subsurface waters (103$502 \mathrm{~m}$ ) are compared with the simulated values in Fig. 8, with model output subsampled from the same month, location, and depth as the observations. There is a strong tendency for the Old BEC model to overestimate iron concentrations at lower iron values in the open ocean subset $(<\sim 0.3 \mathrm{nM}$, Fig. 8a and c). This tendency is reduced in the New BEC simulation, which did not include the progressive decrease in scavenging rates at low-iron concentrations used in the Old BEC (Fig. $8 \mathrm{~b}$ and d). Thus, a first-order dependence on sinking particle concentration (iron concentration $<0.6 \mathrm{nM}$ ) provides a better fit to the observations. In general, the New BEC simulation is improved relative to the old BEC simulation in terms of the observations. The correlation coefficient $\mathrm{R}$ of the log-transformed data increases from 0.40 to 0.60 $(+50 \%)$ in surface waters (Fig. 8a and b), and from 0.49 to $0.60(+23 \%)$ in subsurface waters (Fig. $8 \mathrm{c}$ and d). Similarly, the root-mean-square difference (after log-transformation) between simulated- and observed-iron values is reduced in the New BEC simulation by $14 \%$ in surface waters and by $8 \%$ in subsurface waters (Fig. 8).

The largest data-model mismatch in the Old BEC simulation comes from data collected along the west coast of South America by Bruland et al. (2005) that strongly reflects iron input from sedimentary sources on the continental margin

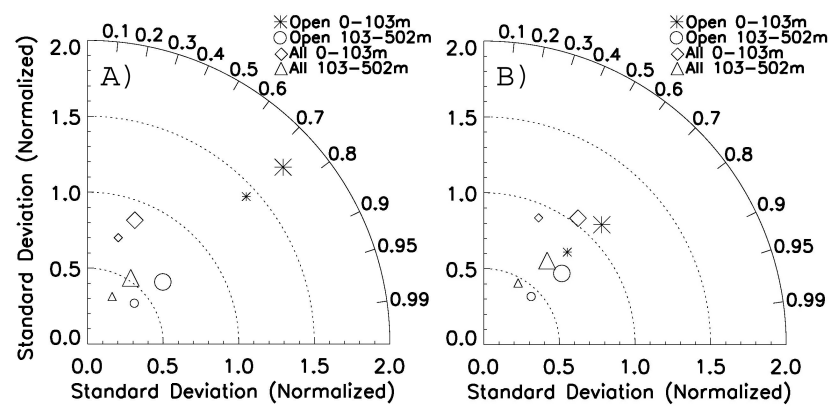

Fig. 9. Normalized Taylor diagrams that compare iron concentrations from the Old BEC (small symbols) and New BEC (large symbols) simulations with the observations, where model output has been sampled at the same month, depth, and location as the observations (A). Another Taylor diagram shows the log-transformed model output and observations (B).

(black " $x$ " symbols in the lower right corner of Fig. 8a). This mismatch is decreased in the New BEC simulation (Fig. 8b). Many of these data points fall along a series of straight lines (constant iron concentration) in the BEC model output, because there are several high resolution onshore-offshore transects, where multiple measurements were made that fall within a single grid box of the BEC model. This highlights one difficulty of comparing field observations with coarseresolution model output. Somewhat apparent in Fig. 8b and $\mathrm{d}$ is the tendency for the New BEC model to overestimate high-end concentrations $(>0.6 \mathrm{nM})$ in surface waters and underestimate high-end concentrations in subsurface waters.

Comparing Figs. $8 \mathrm{~b}$ and d, there is greater scatter around the one-to-one line (and higher rms difference) in surface waters than in subsurface waters. This largely reflects uncertainties associated with our understanding of biological uptake and removal from the euphotic zone. This removal is affected by numerous parameters in the model including the half-saturation values for iron uptake by the different phytoplankton groups. Other model inaccuracies such as mixed layer depths, upwelling rates, and the concentrations of the other nutrients also impact this biological removal in surface waters. Thus, subsurface iron concentrations may offer a better indicator of how well the scavenging parameterizations for iron are working in the model.

To better quantify model-data agreement, we also show summary statistics in Fig. 9 on Taylor diagrams (Taylor, 2001). The standard deviation is greater and generally in better agreement with the observations in the New BEC simulation in both raw and log-transformed data (Fig. 9a and b). The higher standard deviation is partly due to higher iron along the continental margins (increased spatial variability, see following section). The raw statistics are dominated by the high-end iron measurements, and the correlation improves only slightly in the New BEC simulation (Fig. 9a). This is expected because we did not modify the high-end, 


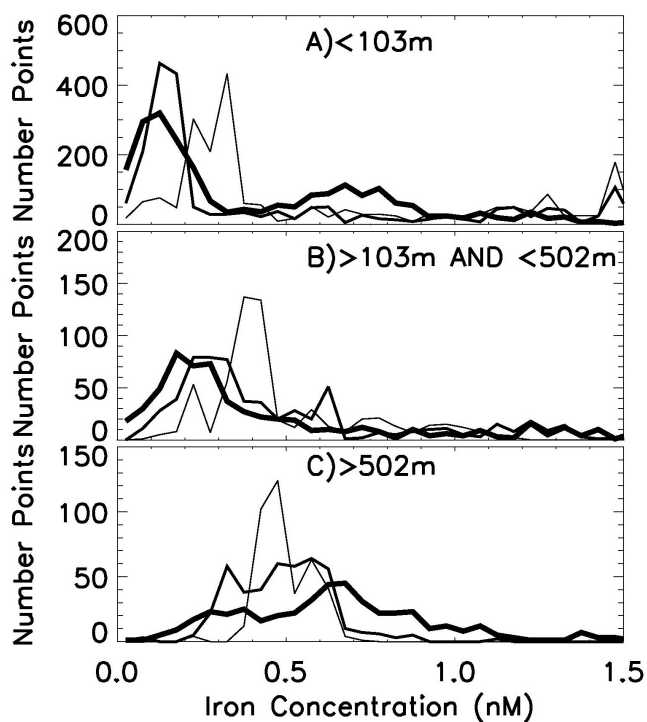

Fig. 10. Binned iron concentration values from the observations (thickest line), the New BEC simulation (medium line), and the Old BEC simulation (thin line) over depth ranges of 0-103 m (A), 103$502 \mathrm{~m}(\mathbf{B})$, and from greater than $502 \mathrm{~m}(\mathbf{C})$.

iron scavenging parameterization. Log transformation of the observations and model output weights more evenly across the range of iron concentrations. There was a larger increase in the correlation coefficients from the Old BEC to the New BEC simulations for the log-transformed data, particularly for the full dataset surface observations. The correlation coefficient $R$ of the log-transformed data increases from 0.40 to 0.60 in surface waters and from 0.49 to 0.60 in subsurface waters for the full observational dataset (Fig. 9b). Thus, much of the improved fit to observations is in the lowend iron concentrations. The standard deviation of the logtransformed model output is within $10 \%$ of that observed for surface waters, whereas the standard deviation in subsurface waters is better in the New BEC simulation, but still underestimates that observed (Fig. 9b).

Observed basin-mean iron concentrations are compared with the New and Old BEC values (Table 1). Deep-ocean values $(>502 \mathrm{~m})$ in the North Atlantic and North Pacific in the New BEC simulations are generally closer to the observed values than are those from the Old BEC simulation, but they remain too low. Mean open-ocean, surface values in the New BEC simulation are 52\% lower in the Southern Ocean and 39\% lower in the North Pacific relative to the Old BEC simulation, and in each case in much better agreement with the field observations (Table 1). Again, much of the model improvement comes in the low-iron regions. Surface values in the North Atlantic and North Indian Oceans are higher in the New BEC simulation than in the observations or the Old BEC simulation.
Another way to evaluate the simulations is to examine the binned distribution of iron over different depth ranges. Figure 10 compares the binned distributions (bin width $0.05 \mathrm{nM}$ ) from our open-ocean subset of the observational database with model output that has been subsampled at the same month, depth, and location as the observations. This gives the model output the same sampling biases present in the observational data, including the decline in the number of observations with increasing depth. The observations have a primary peak in the surface distribution at low iron concentrations $(<0.2 \mathrm{nM}$, Fig. 10a). This primary peak is shifted to progressively higher values as depth increases $(\sim 0.15-$ $0.35 \mathrm{nM}$ in subsurface, Fig. 10b, and a broader peak in the deep ocean centered on $\sim 0.6-0.7 \mathrm{nM}$, Fig. 10c).

At all depth ranges, the New BEC simulation has binned distributions much closer to the observations than the Old BEC (Fig. 10). Both the observations and the New BEC simulation have a strong, low-iron peak in surface waters $(\sim 0.05-0.2 \mathrm{nM})$ with a secondary broader peak centered at $\sim 0.7 \mathrm{nM}$. This high-end peak is much larger in the observations, and both BEC simulations have additional peaks where iron concentrations are greater than $1.2 \mathrm{nM}$. This illustrates that the BEC model generally overestimates high-end iron concentrations in surface waters. In subsurface waters (103$502 \mathrm{~m}$, Fig. 10b), the low iron peak from the New BEC simulation is also in better agreement with the observations than the Old BEC simulation, but it is shifted to slightly higher iron concentrations. In the deeper ocean $(>502 \mathrm{~m})$, the Old BEC simulation has a narrow distribution peaking between $0.45-0.5 \mathrm{nM}$. The New BEC simulation has a broader distribution as also seen in the observations (Fig. 10c). Here both the New and Old BEC models underestimate observed concentrations above $0.65 \mathrm{nM}$, revealing a consistently low bias for high-end iron concentrations in the deep-ocean.

In Figs. 11-14, we compare the spatial patterns of annual mean iron concentration over several depth ranges for all simulations. Observations are also shown as averages on our ocean grid over the same depth ranges. We focus first on differences between the Old BEC and New BEC simulations. The New BEC simulation has high-iron concentrations in surface waters along the continental margins in many regions due to the improved sedimentary source (Fig. 11b). A similar pattern is seen in the observational data in the eastern North and South Pacific, in the southwestern Ross Sea, and south of Australia, essentially wherever onshoreoffshore transects for dissolved iron are available (Fig. 11e). In both the model and the observations, these high-iron concentrations generally do not extend far from the continental source regions, because they are depleted by high scavenging rates and biological uptake in surface waters. In the subsurface observations and in the New BEC simulation, the influence of the continental shelf source often extends further offshore (Figs. 12-14 panels b and e). In particular, for the sub-euphotic zone observations in the North Pacific (and in the New BEC simulation), there is a consistent pattern of 
Table 1. Mean observed and simulated dissolved iron concentrations (nM) in different ocean basins. ${ }^{\text {a }}$

\begin{tabular}{|c|c|c|c|c|c|c|}
\hline \multirow[b]{2}{*}{ Region and Depth } & \multicolumn{3}{|c|}{ Open Ocean } & \multicolumn{3}{|c|}{ All Ocean } \\
\hline & Observed & Old & New & Observed & Old & New \\
\hline \multicolumn{7}{|l|}{ North Indian } \\
\hline $0-103 \mathrm{~m}$ & 0.99 & 1.34 & 1.57 & 1.21 & 1.26 & 1.53 \\
\hline $103-502 \mathrm{~m}$ & 1.43 & 0.88 & 1.12 & 1.50 & 0.89 & 1.12 \\
\hline \multicolumn{7}{|l|}{ North Atlantic } \\
\hline $0-103 \mathrm{~m}$ & 0.72 & 0.96 & 1.01 & 0.68 & 0.97 & 1.05 \\
\hline $103-502 \mathrm{~m}$ & 0.60 & 0.59 & 0.61 & 0.61 & 0.59 & 0.63 \\
\hline 502-945 m & 0.78 & 0.60 & 0.64 & 0.76 & 0.60 & 0.64 \\
\hline$>945 \mathrm{~m}$ & 0.73 & 0.60 & 0.64 & 0.76 & 0.57 & 0.62 \\
\hline \multicolumn{7}{|l|}{ South Atlantic } \\
\hline $0-103 \mathrm{~m}$ & 0.45 & 0.59 & 0.61 & 0.44 & 0.57 & 0.57 \\
\hline \multicolumn{7}{|l|}{ North Pacific ${ }^{b}$} \\
\hline $0-103 \mathrm{~m}$ & 0.20 & 0.28 & 0.17 & 0.31 & 0.25 & 0.22 \\
\hline $103-502 \mathrm{~m}$ & 0.40 & 0.41 & 0.46 & 0.69 & 0.40 & 0.49 \\
\hline 502-945 m & 0.67 & 0.47 & 0.52 & 0.84 & 0.45 & 0.53 \\
\hline$>945 \mathrm{~m}$ & 0.77 & 0.49 & 0.45 & 0.89 & 0.48 & 0.48 \\
\hline \multicolumn{7}{|l|}{ Equatorial Pacific ${ }^{c}$} \\
\hline $0-103 \mathrm{~m}$ & 0.11 & 0.14 & 0.081 & 0.84 & 0.11 & 0.23 \\
\hline $103-502 \mathrm{~m}$ & 0.29 & 0.26 & 0.20 & 0.98 & 0.25 & 0.24 \\
\hline$>945 \mathrm{~m}$ & 0.64 & 0.40 & 0.39 & 1.10 & 0.40 & 0.38 \\
\hline \multicolumn{7}{|l|}{ South Pacific ${ }^{d}$} \\
\hline $0-103 \mathrm{~m}$ & - & - & - & 0.31 & 0.085 & 0.12 \\
\hline \multicolumn{7}{|l|}{ Southern Ocean ${ }^{\mathrm{e}}$} \\
\hline $0-103 \mathrm{~m}$ & 0.17 & 0.31 & 0.15 & 0.50 & 0.31 & 0.21 \\
\hline $103-502 \mathrm{~m}$ & 0.23 & 0.40 & 0.31 & 0.43 & 0.41 & 0.34 \\
\hline $502-945 \mathrm{~m}$ & 0.28 & 0.43 & 0.36 & 0.39 & 0.45 & 0.34 \\
\hline$>945 \mathrm{~m}$ & 0.41 & 0.40 & 0.39 & 0.49 & 0.48 & 0.37 \\
\hline
\end{tabular}

${ }^{a}$ Basins and depths with less than 20 observations are not shown, surface waters always had $>200$ observations per basin. Old and New BEC output were sub-sampled at the month, depth, and location of the observations. ${ }^{b}$ North of $15^{\circ} \mathrm{N}$. ${ }^{\mathrm{c}}$ From $15^{\circ} \mathrm{S}-15^{\circ} \mathrm{N} .{ }^{\mathrm{d}}$ From $15^{\circ} \mathrm{S}-40.5^{\circ} \mathrm{S}$.

e South of $40.5^{\circ} \mathrm{S}$.

higher iron concentrations along the margins, decreasing towards the center of the basin (Figs. 12-14 panels b and e).

Another distinct pattern in the subsurface observations is the tendency for higher sub-euphotic zone iron concentrations in the mid-to-high latitude North Pacific than in the open Southern Ocean (Figs. 4, 5, 12e and 13e). This pattern is generally captured in the New BEC simulation, but not in the Old BEC simulation (Figs. 12 and 13, compare panels $\mathrm{a}, \mathrm{b}$, and e). In the Old BEC simulation, where dissolved iron is mainly driven by dust inputs, the North Pacific has iron concentrations that are only marginally higher than in the Southern Ocean. Partly, the improved sedimentary iron source allows the New BEC simulation to capture this observed pattern. Another factor is that we impose that a higher fraction of the scavenged iron is put onto sinking particles.

Comparing the New BEC and SedOnly simulations reveals the expected dramatic decrease in surface-iron concentration in the North Atlantic and North Indian Oceans when there is no dust source for iron (Fig. 11 panels $b$ and c). There is a decline in surface and subsurface iron concentra- tions across the Pacific not only for the sediment-only simulation (Figs. 11-14 panel c) but also in the dust-only simulation (Figs. 11-14 panel d). Thus, both sources contribute substantially to open-ocean iron concentrations. There is a similar pattern in most other areas outside the high dust deposition areas in the North Atlantic and North Indian Oceans. Comparing panels b-d in Figs. 12 and 13, it can be seen that the elevated iron concentrations in the northwest North Pacific are mainly driven by the sedimentary iron source that is mixed and advected offshore, with a lesser contribution from dust deposition. The sedimentary source is also a more substantial source than dust in the eastern tropical Pacific (panels b-d in Figs. 11 and 12). Similarly, in the western tropical Pacific, a plume of sediment-derived iron flows to the east just north of the equator (but with concentrations below the observations in this area, Figs. 11 and 12).

In several basins, western boundary currents advect iron from the continental source into the open ocean at high latitudes (panels b and c in Figs. 11-14). This is particularly apparent in the Gulf Stream and Kuroshio currents. In the 


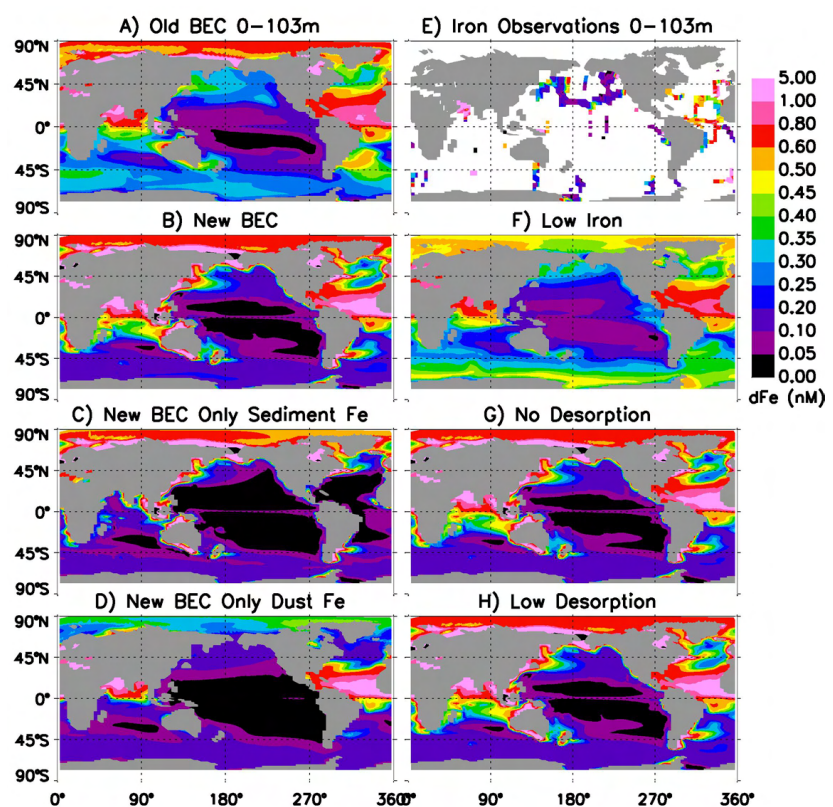

Fig. 11. Annual mean iron concentrations between 0 and $103 \mathrm{~m}$ for all simulations compared with the iron observations averaged onto the model grid over the same depth range.

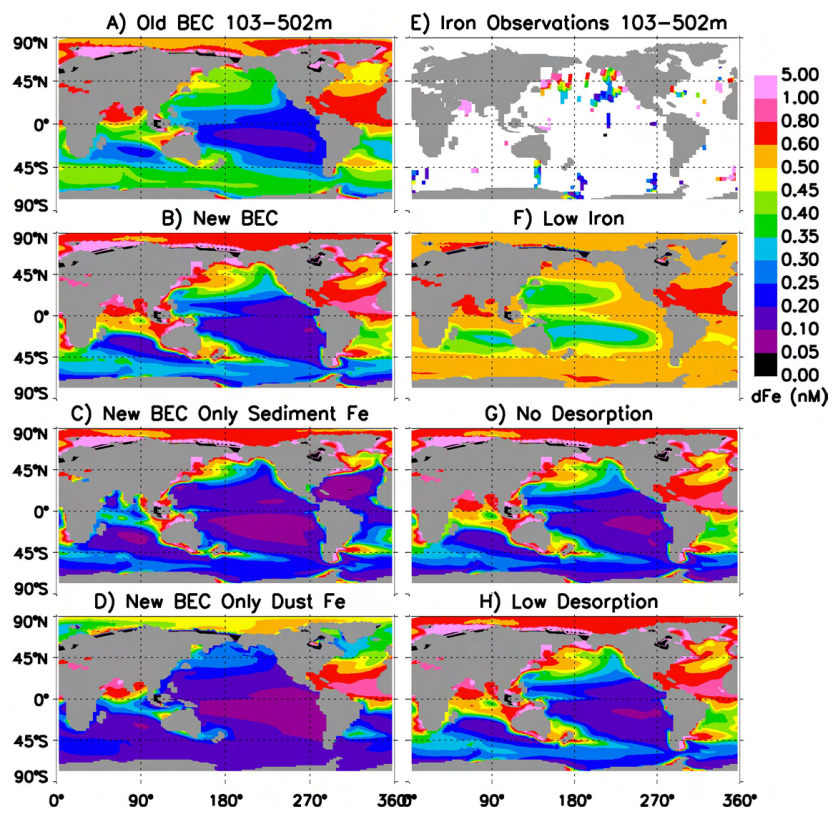

Fig. 12. Annual mean iron concentrations between 103 and $502 \mathrm{~m}$ for all simulations compared with the iron observations averaged onto the model grid over the same depth range.

sub-euphotic zone Southern Ocean, plumes with elevated dissolved-iron concentrations extend for hundreds to thousands of kilometers downstream of sediment-source regions around New Zealand and in the SW Atlantic sector (Figs. 12b and 13b). Less particle export in the Southern Ocean and thus

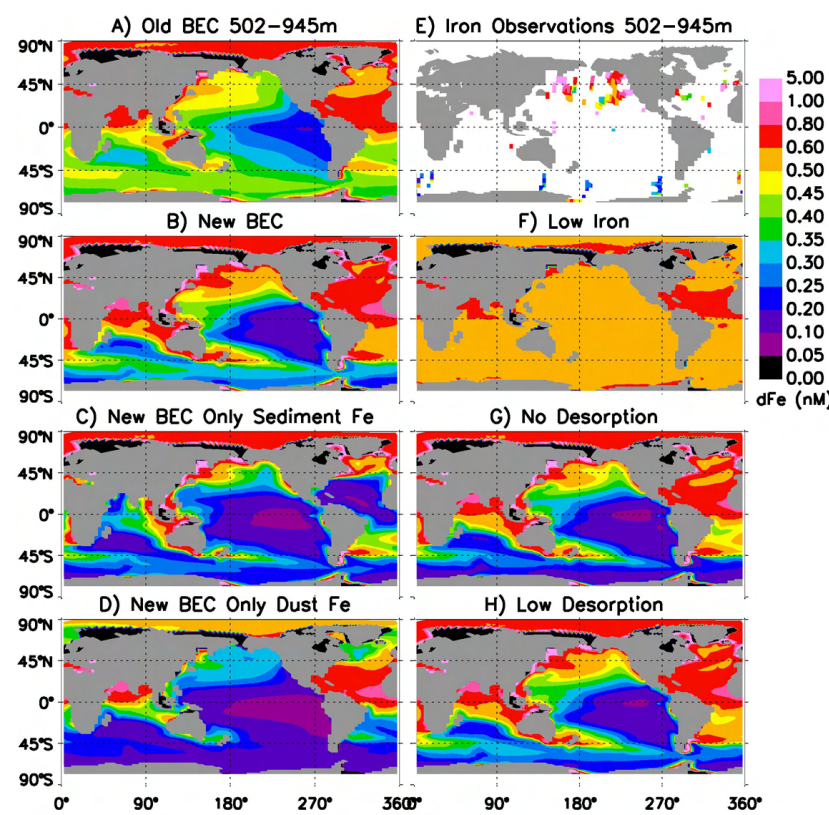

Fig. 13. Annual mean iron concentrations between 502 and $945 \mathrm{~m}$ for all simulations compared with the iron observations averaged onto the model grid over the same depth range.

weaker scavenging loss allows dissolved iron to be advected farther from source regions. Such rapid, long-range transport by the Antarctic Polar Front of sedimentary-derived iron is suggested to account for the high concentrations of iron observed along $6^{\circ} \mathrm{W}$ in the Southern Ocean (de Baar et al., 1995; Löscher et al., 1997; see Figs. 11e and 12e). Our results support this idea, although iron is more depleted in the simulations than in the observations by the time it reaches this location (compare Fig. 12 panels c and e). Our coarseresolution model does not capture the narrow, fast current associated with the Antarctic Polar Front, so there is more time for iron removal during the longer transit in the model.

To further gauge the relative influences of the sedimentary and mineral dust sources for iron, we calculated the basinscale mean iron concentrations for each of our simulations (Table 2). Compared with the New BEC simulation, surfaceiron concentrations in the SedOnly simulation decline by $73 \%$ and $63 \%$ in the North Atlantic and North Indian Oceans, which is not surprising given the recognized importance of dust deposition in these regions. However, in the DustOnly simulation, iron declined by $19 \%$ and $14 \%$ in the North Atlantic and North Indian basins, indicating some influence of the sedimentary iron source on the basin-mean iron concentration even in these high dust deposition areas. A very strong sedimentary influence was seen in the North Pacific, where mean surface-iron concentration declined by $72 \%$ in the DustOnly simulation relative to the New BEC simulation (Table 2). Some of this is due to the large decreases in iron concentrations (more than an order of magnitude) in the 
Table 2. Simulated annual-mean dissolved-iron concentrations (nM) from selected ocean basins and depths ${ }^{\mathrm{a}}$.

\begin{tabular}{|c|c|c|c|c|c|c|c|}
\hline & Old & New & SedOnly & DustOnly & LowFe & NoDesorp & LowDesorp \\
\hline \multicolumn{8}{|l|}{ N. Indian } \\
\hline $0-103 \mathrm{~m}$ & 0.77 & 0.95 & $0.35(-63)$ & $0.81(-14)$ & $0.66(-31)$ & $0.94(-1.1)$ & $0.95(0.0)$ \\
\hline $103-502 \mathrm{~m}$ & 0.63 & 0.77 & $0.37(-52)$ & $0.67(-13)$ & $0.61(-21)$ & $0.73(-5.2)$ & $0.75(-2.6)$ \\
\hline $502-945 \mathrm{~m}$ & 0.64 & 0.78 & $0.40(-49)$ & $0.73(-6.4)$ & $0.60(-23)$ & $0.74(-5.1)$ & $0.76(-2.6)$ \\
\hline$>945 \mathrm{~m}$ & 0.63 & 0.93 & $0.55(-41)$ & $0.86(-7.5)$ & $0.65(-30)$ & $0.87(-6.5)$ & $0.91(-2.2)$ \\
\hline \multicolumn{8}{|l|}{ N. Atlantic } \\
\hline $0-103 \mathrm{~m}$ & 0.68 & 0.80 & $0.22(-73)$ & $0.65(-19)$ & $0.62(-23)$ & $0.78(-2.5)$ & $0.79(-1.3)$ \\
\hline $103-502 \mathrm{~m}$ & 0.62 & 0.74 & $0.29(-61)$ & $0.64(-18)$ & $0.61(-18)$ & $0.72(-2.7)$ & $0.73(-1.4)$ \\
\hline $502-945 \mathrm{~m}$ & 0.63 & 0.71 & $0.32(-55)$ & $0.64(-9.9)$ & $0.60(-16)$ & $0.68(-4.2)$ & $0.70(-1.4)$ \\
\hline$>945 \mathrm{~m}$ & 0.61 & 0.81 & $0.49(-40)$ & $0.73(-9.9)$ & $0.62(-24)$ & $0.74(-8.6)$ & $0.78(-3.7)$ \\
\hline \multicolumn{8}{|c|}{ N. Pacific $\left(>15^{\circ} \mathrm{N}\right)$} \\
\hline $0-103 \mathrm{~m}$ & 0.25 & 0.32 & $0.21(-34)$ & $0.091(-72)$ & $0.21(-34)$ & $0.30(-6.3)$ & $0.31(-3.1)$ \\
\hline $103-502 \mathrm{~m}$ & 0.39 & 0.49 & $0.37(-25)$ & $0.23(-53)$ & $0.49(0.0)$ & $0.46(-6.1)$ & $0.48(-2.0)$ \\
\hline $502-945 \mathrm{~m}$ & 0.47 & 0.55 & $0.42(-24)$ & $0.30(-36)$ & $0.59(+7.3)$ & $0.48(-13)$ & $0.52(-5.5)$ \\
\hline$>945 \mathrm{~m}$ & 0.49 & 0.53 & $0.45(-15)$ & $0.34(-36)$ & $0.54(+1.9)$ & $0.37(-30)$ & $0.46(-13)$ \\
\hline \multicolumn{8}{|c|}{ Equatorial Pacific } \\
\hline $0-103 \mathrm{~m}$ & 0.11 & 0.16 & $0.14(-13)$ & $0.030(-82)$ & $0.14(-13)$ & $0.16(0.0)$ & $0.16(0.0)$ \\
\hline $103-502 \mathrm{~m}$ & 0.26 & 0.25 & $0.19(-24)$ & $0.11(-56)$ & $0.49(+96)$ & $0.22(-12)$ & $0.24(-4.0)$ \\
\hline $502-945 \mathrm{~m}$ & 0.31 & 0.29 & $0.21(-28)$ & $0.22(-24)$ & $0.59(+104)$ & $0.24(-17)$ & $0.27(-6.9)$ \\
\hline$>945 \mathrm{~m}$ & 0.35 & 0.40 & $0.35(-13)$ & $0.22(-45)$ & $0.52(+30)$ & $0.31(-23)$ & $0.36(-10)$ \\
\hline \multicolumn{8}{|c|}{ Southern Ocean } \\
\hline $0-103 \mathrm{~m}$ & 0.29 & 0.20 & $0.15(-25)$ & $0.12(-40)$ & $0.35(+75)$ & $0.19(-5.0)$ & $0.19(-5.0)$ \\
\hline $103-502 \mathrm{~m}$ & 0.39 & 0.34 & $0.28(-18)$ & $0.18(-47)$ & $0.57(+68)$ & $0.29(-15)$ & $0.32(-6.9)$ \\
\hline $502-945 \mathrm{~m}$ & 0.43 & 0.37 & $0.30(-19)$ & $0.19(-68)$ & $0.60(+62)$ & $0.28(-24)$ & $0.33(-11)$ \\
\hline$>945 \mathrm{~m}$ & 0.45 & 0.50 & $0.46(-8.0)$ & $0.32(-36)$ & $0.59(+18)$ & $0.38(-24)$ & $0.45(-10)$ \\
\hline
\end{tabular}

a Values in parentheses show the \% difference from the New BEC simulation.

coastal regions, but as illustrated in Figs. 11-14, open-ocean concentrations are also affected. Removing the dust source for iron in this region decreases mean iron concentration by $34 \%$ in the North Pacific. A similar pattern is seen in the equatorial Pacific where mean iron concentration declined by $82 \%$ in surface waters, and $56 \%$ in subsurface waters in the DustOnly simulation. The Southern Ocean mean iron concentration also decreased by $40 \%$ in surface waters without the sediment source, and by $25 \%$ without the dust source for iron (Table 2). In each case there is a contribution towards the basin-mean value from the large, localized reductions along the continental margins, and a contribution from more modest reductions in the open ocean. To distinguish between these margin and open-ocean effects, we computed mean iron concentrations in the open-ocean North Pacific (160$220^{\circ} \mathrm{E}$ and $15-45^{\circ} \mathrm{N}$ ) in these three simulations, with mean iron concentrations of $0.18 \mathrm{nM}$ for the New BEC, $0.069 \mathrm{nM}$ for the SedOnly, and $0.085 \mathrm{nM}$ for the DustOnly simulations. Thus, removing the dust source reduced open-ocean iron concentrations by $62 \%$, whereas removing the sediment source decreased those same concentrations by $53 \%$. Both sources affect open-ocean iron distributions, with a somewhat stronger influence from dust.

We also examined the impacts of each iron source on globally integrated primary production, export production, and nitrogen fixation by comparing output from the New BEC, SedOnly, and DustOnly simulations. Due to its more diffuse input pattern, the removal of the dust source had a stronger impact on these global-scale biogeochemical fluxes (Table 3). Primary production in the SedOnly simulation was reduced by $15 \%$ relative to the New BEC simulation, with export production reduced by $18 \%$ and nitrogen fixation reduced by $48 \%$. In the DustOnly simulation, primary production was reduced by $5 \%$, export production by $10 \%$, and nitrogen fixation by $30 \%$, relative to the New BEC simulation. Thus, both sources for dissolved iron contribute substantially in driving productivity and ocean biogeochemical cycles, with a somewhat stronger impact by the mineral dust iron source. The changes in $\mathrm{N}$ fixation were dominated by the Pacific basin and parts of the South Indian and South Atlantic Oceans where iron limits growth. Phosphorus-limited diazotrophs grow in the tropical Atlantic and North Indian Oceans. The other phytoplankton groups responded most strongly in the Pacific and Southern Oceans where large areas are iron limited and both iron sources contribute substantially to dissolved-iron concentrations.

Despite the large changes in mean iron concentrations (Table 2), corresponding changes in other carbon-cycle variables are relatively smaller. There are large decreases in iron concentrations beneath the main dust plumes in the SedOnly 
Table 3. Simulated global-scale fluxes from the New BEC simulation and sensitivity tests ${ }^{\mathrm{a}}$.

\begin{tabular}{lcccccc}
\hline & NewBEC & SedOnly & DustOnly & LowFe & NoDesorp & LowDesorp \\
\hline $\mathrm{PP}^{\mathrm{b}}$ & 46.9 & $40.1(-15)$ & $44.5(-5.1)$ & $45.4(-3.2)$ & $46.7(-0.43)$ & $46.8(-0.21)$ \\
ExpP $^{\mathrm{c}}$ & 5.76 & $4.75(-18)$ & $5.16(-10)$ & $6.05(+5.0)$ & $5.71(-0.87)$ & $5.74(-0.35)$ \\
Nfix $^{\mathrm{d}}$ & 136 & $70.9(-48)$ & $94.6(-30)$ & $127(-6.6)$ & $134(-1.5)$ & $135(-0.74)$ \\
Diat\% & 38 & 62 & 59 & 14 & 40 & 39 \\
Diaz\% & 40 & 64 & 65 & 46 & 41 & 39 \\
Sp\% & 38 & 60 & 51 & 19 & 39 & 38 \\
\hline
\end{tabular}

${ }^{a}$ Numbers in parentheses show the percent change relative to the New BEC simulation. ${ }^{b}$ Primary production $\left(\mathrm{PgC} \mathrm{yr}^{-1}\right) .{ }^{\mathrm{c}} \mathrm{Export}^{\mathrm{Produc}-}$ tion $\left(\mathrm{PgC} \mathrm{yr}^{-1}\right){ }^{\mathrm{d}}$ Nitrogen Fixation $\left(\mathrm{TgN} \mathrm{yr}^{-1}\right)$. ${ }^{\mathrm{e}}$ The percentage of ocean area where iron limits growth for the diatoms, diazotrophs, and small phytoplankton.

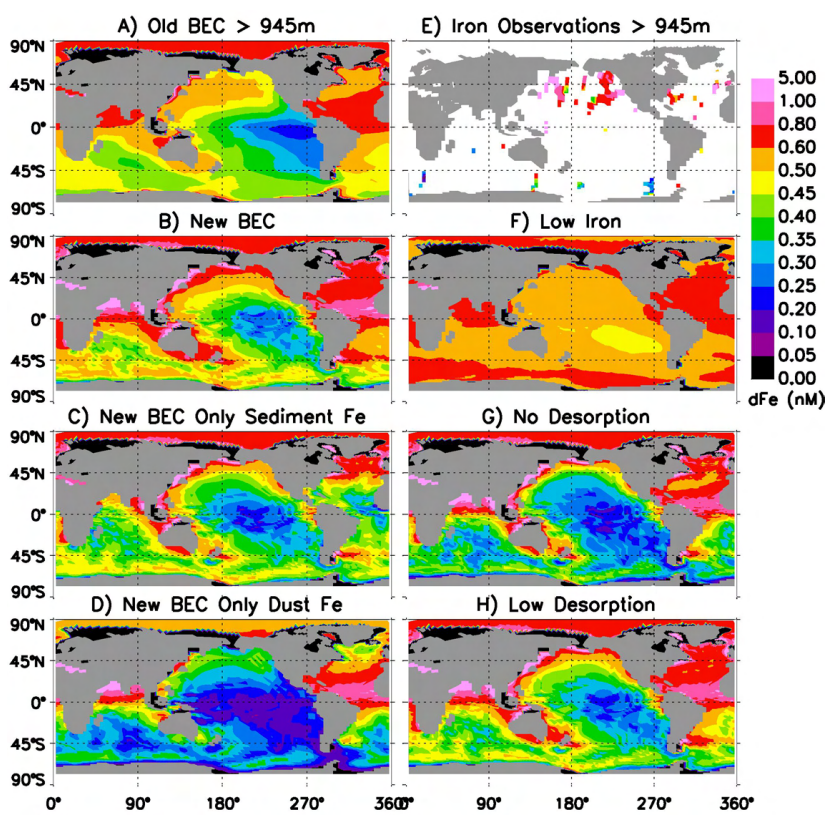

Fig. 14. Annual mean iron concentrations for waters deeper than $945 \mathrm{~m}$ for all simulations compared with the iron observations averaged onto the model grid over the same depth range.

simulation and in shallow waters along the continental margins in the DustOnly simulation. In each case, much of this decrease is "excess" iron that would otherwise be removed by scavenging in these iron-replete regions. Also, because scavenging rates of dissolved iron in the model progressively increase with iron concentrations above $0.6 \mathrm{nM}$, removing either iron source lowers iron concentrations, decreasing scavenging losses for the other source as iron concentrations are reduced in high-iron areas. Even outside these high-iron areas, some of the iron decrease occurs in places where iron does not limit phytoplankton growth rates. Lastly, there is a downstream effect, where reductions in production and export in HNLC regions are partially offset by increases elsewhere due to lateral transport of nutrients (see Dutkiewicz et al., 2005).
In our New BEC simulation, each phytoplankton functional group is iron-limited in their growth over $\sim 38 \%$ of the oceans (Table 3). The spatial patterns vary by group with iron-limitation for the small phytoplankton and diatoms concentrated in the HNLC regions, and iron-limitation for the diazotrophs spread over much of the tropics and subtropics (see Moore et al., 2004). In the SedOnly and DustOnly simulations these iron-limited areas increase dramatically to approximately $60 \%$ for each group (Table 1), with much of the increase in the Pacific basin where both sources contribute strongly to open-ocean iron distributions.

We next compare output from the New BEC simulation with the LowFe, NoDesorp, and HighDesorp sensitivity simulations (Figs. 11-14). Including an explicit desorption of iron from sinking particles has little effect on surface waters, increasing dissolved iron concentrations by only a few percent in most regions (compare New BEC with NoDesorp and LowDesorp cases in Fig. 11, panels b, g, and h, Table 2). This is because the release of iron from particle desorption is quite small relative to the forward scavenging rate onto particles. The similarity in surface-iron concentrations in these simulations leads to similar global biogeochemical fluxes (Table 3).

Deeper in the ocean where particle scavenging is reduced, desorption from particles increases iron concentrations substantially in some regions, i.e., by $30 \%$ in the deep North Pacific, by $23 \%$ in the deep equatorial Pacific, and by $24 \%$ in the Southern Ocean (Table 2, Figs. 12-14 panels b, g, and h). The LowDesorp simulation has iron concentrations in between the New BEC and NoDesorp cases. In deep-ocean areas where iron concentrations exceed $0.6 \mathrm{nM}$, desorption has less effect due to the nonlinearity in scavenging rates. Thus, these three simulations have similar deep-ocean concentrations in the deep North Atlantic and North Indian oceans, but differ markedly in the North Pacific and Southern Ocean (Fig. 14, panels b, g, and h). 
Comparing the New BEC simulation and the LowFe simulation, both simulations have similarly low concentrations in the lower latitude surface waters, away from the high dust deposition regions (Fig. 11, panels b and f). In the subsurface waters though, the LowFe simulations has very high iron concentrations ( $>0.5 \mathrm{nM}$ in most regions), well above the observed values (Fig. 12, panels b, e, and f). Even with the very low (minimal) iron inputs in this simulation, subsurface-iron concentrations are grossly overestimated when there is no scavenging of the low-end iron concentrations $(<0.6 \mathrm{nM})$. Elevated subsurface-iron concentrations strongly affect surface waters in regions of deeper winter mixing and upwelling, such as in the Southern Ocean and eastern equatorial Pacific (Fig. 13b). Averaged over the equatorial Pacific, surface concentrations in the LowFe simulation are slightly lower than in the New BEC simulation $(0.14 \mathrm{nM}$ vs. $0.16 \mathrm{nM}$ ), whereas its subsurface concentrations are nearly twice those in the New BEC simulation (Table 2). Southern Ocean surface iron concentrations in the LowFe simulation are $75 \%$ higher and subsurface iron concentrations are $68 \%$ higher than in the New BEC simulation; they are also much higher than the observations (Tables 1 and 2, Fig. 12). Thus, surface iron fields are not a good gauge of model behavior because biological drawdown keeps iron at reasonable concentrations, even when the inputs from subsurface waters are much too high. In the deep ocean, iron concentrations in the LowFe simulations are slightly above $0.6 \mathrm{nM}$ in regions underlying the major dust plumes, and slightly below $0.6 \mathrm{nM}$ elsewhere, and once again there is a poor match to the observed iron distributions (Fig. 14, panels e and f, Table 2). The New BEC simulation is in better agreement with the observations than the Old BEC simulation in the North Pacific ocean at shallow and mid-water depths (Figs. 11-13, panels $\mathrm{a}, \mathrm{b}$ and e). However, in the deep ocean the model still underestimates the observed concentrations in this region (Fig. 14). Further increasing the desorption rate could increase simulated concentrations in the deep North Pacific, but would also push other regions, such as the Southern Ocean to concentrations that are above those observed.

\section{Discussion}

Our results indicate a strong influence of the continental margin iron source on both the basin-mean and open-ocean iron concentrations, and on biological productivity, nitrogen fixation, and the export of organic matter from surface waters. Inputs from mineral dust deposition have a stronger impact on open-ocean iron concentrations and biogeochemical cycling, but the sedimentary source was substantial in all regions, except perhaps beneath the large dust plumes in the North Atlantic and northern Indian Oceans. Ocean biogeochemical models should include a sedimentary source for iron, as suggested by Elrod et al. (2004). Models without this source will overestimate the biogeochemical sensitivity to variations in dust deposition to the oceans (i.e., Moore et al., 2006; Parekh et al., 2006). Both high particle scavenging rates and biological uptake often remove the high-iron, continental signal close to the coasts in surface waters, but in subsurface waters, where losses are reduced, this continental signal can travel far from margin source regions.

There remains considerable uncertainty regarding the strength of each of these two major sources for dissolved iron. There are very few observations of dust deposition to constrain the atmospheric dust entrainment and transport models. One factor not accounted for here is variations in the solubility of $\mathrm{Fe}$ in mineral dust. Solubility may be lower near source regions than our assumed 2\% (i.e., Baker et al., 2006). Also, a number of recent studies suggest that our solubility of $2 \%$ (or the $1 \%$ often used in other studies) could be too low by an order of magnitude or more in regions far from dust source areas (i.e., see Luo et al., 2005 and references therein; Sedwick et al., 2005; Fan et al., 2006; Baker et al., 2006). One uncertainty in our sedimentary source is missing offshore transport in the model due to eddies and other mesoscale physical processes, which likely play an important role (Johnson et al., 2005; Lam et al., 2006). Similarly, the model advects only dissolved iron offshore, even though small particulates are also likely to contribute (Lam et al., 2006). The model probably underestimates the local scavenging loss of iron near sedimentary source regions, as the flux from a small area (often only a few percent of our grid box) is instantly diluted throughout the model grid cell, resulting in much lower concentrations than would exist in a finer resolution model (or in situ). There is a large uncertainty about how much of the iron flux from the sediments estimated by Elrod et al. (2004) would be scavenged locally. Our results are also extrapolated from a relatively small set of observations (Elrod et al., 2004) on the continental margin, and rely on model estimates of the organic carbon flux to the sediments, which may be too low to drive the sedimentary release of iron. This study also neglects the riverine source of dissolved iron to the oceans.

Including explicit desorption of iron from sinking particles improved the fit to observations in the deep ocean (increasing deep-ocean concentrations by up to $30 \%$ in some regions), but it had little impact on surface-iron concentrations and upper-ocean biogeochemical cycling. This is similar to what has been suggested for ${ }^{234} \mathrm{Th}$, where desorption is generally negligible in surface waters, because high particle concentrations lead to strong scavenging removal (i.e., Bruland and Lohan, 2004). There is insufficient observational data to determine if desorption plays an important role in the marine iron cycle. In the upper ocean, modelers may be able to ignore desorption of iron in favor of a net scavenging rate onto particles.

We have optimized the iron scavenging parameterization for our model configuration, assuming a consistent relation to sinking particle mass and an increased scavenging rate at high-iron concentrations. The values of $\mathrm{Fe}_{\mathrm{b}}$ and Chigh are 
Table 4. Residence time for dissolved iron estimated from the New BEC simulation ${ }^{\mathrm{a}}$.

\begin{tabular}{|c|c|}
\hline Depth-Area Considered & Residence Time (Years) \\
\hline Upper 103 m Global & 0.65 \\
\hline Upper 103 m High Iron ${ }^{b}$ & 0.45 \\
\hline Upper 103 m Low Iron ${ }^{c}$ & 1.4 \\
\hline Upper 502 m Global & 2.3 \\
\hline Upper 502 m High Iron ${ }^{b}$ & 1.1 \\
\hline Upper $502 \mathrm{~m}$ Low Iron ${ }^{\mathrm{c}}$ & 6.2 \\
\hline All Depths Global & 12 \\
\hline All Depths High Iron ${ }^{d}$ & 5.6 \\
\hline All Depths Low Iron ${ }^{\mathrm{e}}$ & 24 \\
\hline
\end{tabular}

a Residence time is calculated as the inventory/(loss due to sinking particles $+10 \%$ of scavenged iron that is lost to the sediments).

b Surface iron concentration $>0.55 \mathrm{nM}$ and/or some sedimentary iron input.

c Surface iron concentration $<=0.55 \mathrm{nM}$ and no sedimentary iron source.

${ }^{\mathrm{d}}$ Surface iron concentration $>0.55 \mathrm{nM}$.

e Surface iron concentration $<=0.55 \mathrm{nM}$.

empirical, having been tuned to have the best match with observed iron distributions. The tuning process would have to be repeated when other model parameters are changed (i.e., remineralization length scales, or assumed $\mathrm{Fe} / \mathrm{C}$ ratios in the biota, etc.) or when using a different physical circulation model. Some field studies have found higher $\mathrm{Fe} / \mathrm{C}$ ratios than the values we used for the BEC model (i.e., $\sim 6-14 \mu \mathrm{mol} / \mathrm{mol}$ increasing to a mean of $40 \mu \mathrm{mol} / \mathrm{mol}$ after iron addition, Twining et al., 2004; 5.5-37 $\mu \mathrm{mol} / \mathrm{mol}$, McKay et al., 2005). Yet others have found lower values similar to those assumed for the BEC model $(\sim 4.4 \mu \mathrm{mol} / \mathrm{mol}$, Blain et al., 2007). Increasing the optimal $\mathrm{Fe} / \mathrm{C}$ much above our assumed value of $6 \mu \mathrm{mol} / \mathrm{mol}$ for the diatoms and small phytoplankton would require a decrease in the base scavenging rate to maintain an optimal match to the observed iron distributions.

Our parameterization for increasing scavenging rates when the dissolved iron concentration exceeds $0.6 \mathrm{nM}$ caused the model to overestimate high-end iron concentrations in surface waters and to underestimate the high-end concentrations in subsurface waters. The optimum value of the coefficient Chigh, used in this parameterization, was several times higher for surface waters than for subsurface waters. At least two factors may be responsible. Iron inputs may be overestimated for surface waters in high dust-deposition regions, as values below our assumed $2 \%$ solubility are observed for fresh Saharan dust (Baker et al., 2006). Also, in these high-scavenging regions, scavenging efficiency may decrease with depth as organic coatings on sinking particles are degraded, or as iron-binding sites on the particles become occupied.
Our results suggest that a model needs relatively strong scavenging removal of iron from sub-euphotic, upper ocean waters in order to match the observations of dissolved iron. This becomes apparent in our simulations with relatively high iron inputs (including the sedimentary source and some subsurface release from dust particles) as well as in the sensitivity experiment with a low-end estimate of iron inputs (LowFe, constant $1 \%$ dissolution from mineral dust). In most regions, the subsurface, dissolved iron concentrations are well below $0.6 \mathrm{nM}$, meaning that nearly all the dissolved iron would be bound to organic ligands (i.e., Rue and Bruland, 1995, 1997; van den Berg, 1995; Wu and Luther, 1995). Therefore, much of this scavenging removal is probably due to aggregation followed by removal onto sinking particles of the colloidal, ligand-bound iron (Wu et al., 2001; Nishioka et al., 2001; de Baar and de Jong, 2001). Models that assume no scavenging of ligand-bound iron may overestimate subsurface-iron concentrations. Explicitly including ligand and aggregation dynamics in the model would be computationally expensive, but it could potentially improve simulations of the marine iron cycle, particularly as we learn more about the cycling of iron-binding ligands. Our assumption in the BEC model that scavenging rates progressively decreased as iron decreased below $0.5 \mathrm{nM}$ was incorrect, and it led to an overestimation of dissolved-iron concentrations at the low end of observations (Figs. 8 and 10). Our more realistic sedimentary iron source and the improved scavenging parameterizations in the New BEC simulation provides an improved fit to the observed iron concentrations.

The residence times for dissolved iron over different depth ranges are summarized in Table 4. Areas with high inputs of iron (where dissolved concentrations exceed $0.6 \mathrm{nM}$ ) have shorter residence times due to higher scavenging rates in the model. Away from the high-iron input regions, upper ocean residence times are 1.4 years for the upper $103 \mathrm{~m}$ and 6.2 years for the upper $502 \mathrm{~m}$. In the highest dust input regions beneath the major plumes, residence times are only 1 or 2 months. The deep-ocean residence time away from the high-iron regions was 24 years, less than the estimate of 70-140 years by Bruland et al. (1994) for the deep North Pacific. De Baar and de Jong (2001) estimated residence time for the surface ocean of a few months, and 1541 years for the deep ocean, assuming a sedimentary source equal to inputs from dust deposition. Our model residence times, which include both sources, are of similar magnitude (Table 4). Parekh et al. (2005) estimated a mean ocean residence time of 233 years, in a simulation with a $1 \%$ surface dissolution of mineral dust as the only source. The higher iron inputs in our simulation require stronger scavenging removal and shorter residence times to maintain realistic iron concentrations. Bergquist and Boyle (2006) estimated a residence time of 270 years based on differences in deep-ocean measurements of dissolved iron at North Atlantic and South Atlantic sites, the estimated transit time between the two sites, and an estimated input of dissolved iron from sinking 
biogenic particles. This estimate assumed an iron-to-carbon ratio equivalent of $10 \mu \mathrm{mol} / \mathrm{mol}$ for estimated inputs from biogenic particles. Although this is a reasonable estimate for biogenic particles produced in the surface ocean, particles releasing iron in the deep ocean might have considerably higher iron content due to scavenging of dissolved iron throughout the overlying water column. Increased iron inputs would substantially increase the estimated scavenging loss for iron and reduce their estimated residence time. Our estimates of dissolved-iron inputs to the oceans (Fig. 7) and our model results suggest a short mean global residence time for iron of at most a few decades, in agreement with the estimate of de Baar and de Jong (2001). This global average is a combination of shorter residence times near the sources and longer residence times elsewhere.

In the surface ocean $(<103 \mathrm{~m})$ there is a bimodal distribution in the observed iron distributions, with a larger peak centered at $\sim 0.1-0.15 \mathrm{nM}$ and a secondary broad peak centered at $\sim 0.6-0.8 \mathrm{nM}$ (Fig. 10a). The high-end iron peak reflects samples mainly from the high dust deposition regions, or where samples from other areas were collected shortly after dust-deposition events. Dust deposition likely varies considerably even within the high-deposition regions, but it seems that when iron concentrations exceed this peak value there is a strong tendency for iron to be removed rapidly by scavenging. There is a similar high-end peak in the observations in the deep ocean (Fig. 10c), suggesting a common controlling process, most likely increased scavenging losses as iron exceeds $\sim 0.6-0.7 \mathrm{nM}$, as suggested by Johnson et al. (1997a). Scavenging losses must increase at higher iron concentrations to match the observed distributions. However, it is not strictly tied to a concentration of $0.6 \mathrm{nM}$. Scavenging likely increases rapidly as iron concentrations exceed $\sim 0.5-1.5 \mathrm{nM}$, depending on local ligand concentrations and dynamics.

There appear to be two distinct scavenging regimes for dissolved iron in the oceans, depending on the balance between iron sources and sinks. At very high iron inputs, as in the high-deposition regions in the North Indian and North Atlantic basins, the strong binding ligands can become saturated, and scavenging rates will increase as an increasing proportion of iron is bound to weaker ligands or exists as free inorganic iron. At lower iron input levels, the aggregation and removal of the colloidal size class combined with biological uptake will decrease surface dissolved iron concentrations to low concentrations $(<0.2 \mathrm{nM})$. This accounts for the surface peak in the observations between $\sim 0.1-0.15 \mathrm{nM}$ in surface waters (Fig. 10). This peak in the distribution is found throughout waters that vary considerably in iron input from the sediments and atmospheric dust deposition from very low input to the equatorial Pacific and Southern Ocean, to moderate input in the higher latitude North Pacific (Fig. 5, Zender et al., 2003; Luo et al., 2003). The combination of particle scavenging and biological uptake appear to deplete surface-iron concentrations down to relatively low, nearly constant levels, despite variations in iron input from dust deposition and lateral transport from the continental margins. Several factors may play a role in this pattern. In some regions, increased iron inputs will lead to higher biological production and export, providing more particles to scavenge and remove dissolved iron. When iron is more plentiful, phytoplankton $\mathrm{Fe} / \mathrm{C}$ ratios will be higher, in part due to luxury uptake by larger diatoms, removing iron more efficiently (Sunda and Huntsman, 1997). Conversely, the number of binned samples declines sharply in our lowest bin $(0.0-0.05 \mathrm{nM})$. As iron falls to very low concentrations $(<0.1 \mathrm{nM})$, the phytoplankton will adapt by lowering their $\mathrm{Fe} / \mathrm{C}$ ratios, thus decreasing the export efficiency. Also, biological uptake will be reduced as the ambient iron concentration approaches or even falls below the half-saturation $\mathrm{Fe}$ uptake values. Lastly, extreme iron limitation will reduce productivity and the formation of biological particles available to scavenge and remove dissolved iron. Less dissolved iron may be in the colloidal size fraction when iron concentrations fall to very low values (Nishioka et al., 2001, 2005). Thus, as iron falls to very low concentrations, both the scavenging loss and biological uptake will be reduced.

A global collection of dissolved iron observations has now accumulated that is sufficient to place some strong constraints on ocean biogeochemical models. There appears to be substantial scavenging removal of iron in areas where ambient concentrations are well below $0.6 \mathrm{nM}$. Thus, models that assume scavenging removal only when iron concentrations exceed this threshold will tend to overestimate subsurface iron concentrations and subsurface $\mathrm{Fe}$ inputs to the euphotic zone. This assumption will tend to over-emphasize the subsurface-iron source and underestimate the importance of dust deposition as a driver of ocean biogeochemical cycling. Thus, it is critical that models be evaluated against observations both at the surface and in the subsurface, which drives much of the iron input to surface waters. Another useful metric is how well models can reproduce the binned distributions of iron observations (Fig. 10).

In the high-deposition regions, observed iron concentrations are often well above $0.6 \mathrm{nM}$, even though this surplus iron signal appears to be removed by scavenging over relatively short timescales (weeks to months), allowing for limited advection. The mean surface-iron concentration for areas outside the high deposition regions is $0.25 \pm 0.23 \mathrm{nM}$, and the mean in the high deposition regions is $0.76 \pm 0.27 \mathrm{nM}$. This is only a three-fold difference in observed, mean iron concentrations, despite variations in iron inputs of several orders of magnitude. The mean concentration for the HNLC regions is $0.15 \pm 0.16 \mathrm{nM}$, only modestly lower than for the non-HNLC regions (excluding high deposition areas), where the mean is $0.27 \pm 0.24 \mathrm{nM}$. These averages include sporadic increases due to dust deposition events (i.e., Bruland et al., 1994; Johnson et al., 2003); otherwise surface values are typically below $0.2 \mathrm{nM}$. The deep North Pacific iron concentrations display strong lateral gradients with high-iron 
concentrations near the continental margins, decreasing towards the center of the basin.

\section{Conclusions}

Fluxes from continental margins and mineral dust deposition are key sources of dissolved iron to the oceans. These sources influence primary production, biological carbon export, and nitrogen fixation at the global scale. Both iron sources should be included in ocean biogeochemical models that include the iron cycle. Biological uptake and scavenging deplete surface concentrations of dissolved iron to low levels in most regions, leading to a bi-modal distribution in surface waters. Relatively strong scavenging removal is required in subsurface waters to match the observed iron distributions. Biogeochemical models that aim to realistically simulate oceanic iron must be validated against the available dissolved iron observations in both surface waters and in the subsurface waters that supply iron to the euphotic zone. The available observational data will increase rapidly over the next decade through ongoing research projects and the surveys associated with the CLIVAR and GEOTRACES programs. The growing global database of iron observations and associated process studies will provide new opportunities to improve our understanding of the marine iron cycle. Future field efforts that document the changing $\mathrm{Fe} / \mathrm{C}$ ratios in sinking matter at multiple depths could provide valuable information on the biotic $\mathrm{Fe} / \mathrm{C}$ ratios and on the rates of removal by iron scavenging. Lagrangian onshore-offshore transects could help constrain scavenging losses and the flux of iron from the margins to the open ocean. An improved understanding of iron interactions with other marine biogeochemical cycles will allow study of climate-biota interactions, and ultimately improve our ability to simulate past and future climate change.

Acknowledgements. We thank all the researchers, technicians, and students who made the iron measurements and made the data publicly available. Also thanks to Payal Parekh, Mick Follows, and Ed Boyle for publishing their iron observations compilation. Thanks also to Olivier Aumont, an anonymous reviewer, and Jim Orr for their helpful comments, which considerably improved the paper. This work is funded by a National Science Foundation grant (NSF OCE-0452972 to J. K. Moore), a grant from NASA (NNX08AB76G) and the UCI Research Experience for Undergraduates (REU) program funded by the National Science Foundation (NSF ATM-0453295 to J. K. Moore).

Edited by: J. Orr

\section{References}

Archer, D. E., and Johnson, K.: A model of the iron cycle in the ocean, Global Biogeochem. Cy., 14, 269-279, 2000.

Armstrong, R. A., Lee, C., Hedges, J. I., Honjo, S., and Wakeham, S. G.: A new, mechanistic model for organic carbon fluxes in the ocean based on the quantitative association of POC with ballast minerals, Deep-Sea Res. II, 49, 219-236, 2002.

Aumont, O. and Bopp, L.: Globalizing results from ocean in situ iron fertilization studies, Global Biogeochem. Cy., 20, GB2017, doi:10.1029/2005GB002591, 2006.

Aumont, O., Maier-Reimer, E., Blain, S., and Monfray, P.: An ecosystem model of the global ocean including $\mathrm{Fe}$, Si, P co-limitations, Global Biogeochem. Cy., 17, 1060, doi:10.1029/2001GB001745, 2003.

Bacon, M. P. and Anderson, R. F.: Distribution of Thorium isotopes between dissolved and particulate forms in the deep sea, J. Geophys. Res., 87, 2045-2056, 1982.

Baker, A. R., Jickells, T. D., Witt, M., and Linge, K. L.: Trends in the solubility of iron, aluminum, manganese and phosphorus in aerosol collected over the Atlantic Ocean, Mar. Chem., 98, 4358, 2006.

Balistrieri, L., Brewer, P. G., and Murray, J. W.: Scavenging residence times of trace metals and surface chemistry of sinking particles in the deep ocean, Deep-Sea Res., 28, 101-121, 1981.

Berelson, W., McManus, J., Coale, K., Johnson, K., Burdige, D., Kilgore, T., Burdige, T., and Pilskaln, C.: Biogenic matter diagenesis on the sea floor: a comparison between two continental margin transects, J. Mar. Res., 54, 731-762, 1996.

Berelson, W., McManus, J., Coale, K., Johnson, K., Burdige, D., Kilgore, T., Colodner, D., Chavez, F., Kudela, R., and Boucher, J.: A time series of benthic flux measurements from Monterey Bay, CA, Continental Shelf Res., 23, 457-481, 2003.

Bergquist, B. A. and Boyle, E. A.: Dissolved iron in the tropical and subtropical Atlantic Ocean, Global Biogeochem. Cy., 20, GB1015, doi:10.1029/2005GB002505, 2006.

Berman-Frank, I., Cullen, J. T., Shaked, Y., Sherrell, R. M., and Falkowski, P. G.: Iron availability, cellular iron quotas, and N fixation in Trichodesmium, Limnol. Oceanogr., 46, 1249-1260, 2001.

Blain, S., Treguer, P., Belviso, S., Bucciarelli, E., Denis, M., Desbre, S., Fiala, M., Jezequel, V. M., LeFevre, J., Mayzaud, P., Marty, J., and Razouls, S.: A biogeochemical study of the island mass effect in the context of the iron hypothesis: Kerguelen Islands, Southern Ocean, Deep-Sea Res. I, 48, 163-187, 2001.

Blain, S., Quéguiner, B., Armand, L., Belviso, S., Bombled, B., et al.: Effect of natural iron fertilization on carbon sequestration in the Southern Ocean, Nature, 446, 1070-1074, 2007.

Bowie, A. R., Achterberg, E. P., Blain, S., Boye, M., Croot, P. L., de Baar, H. J. W., Laan, P., Sarthou, G., and Worsfold, P. J.: Shipboard analytical intercomparison of dissolved iron in surface waters along a north-south transect of the Atlantic Ocean, Mar. Chem., 84, 19-34, 2003.

Bowie, A. R., Achterberg, E. P., Croot, P. L., de Baar, H. J. W., Laan, P., Moffett, J. W., Ussher, S., and Worsfold, P. J.: A communitywide intercomparison exercise for the determination of dissolved iron in seawater, Mar. Chem., 98, 81-99, 2006.

Boyd, P. W. and Doney, S. C.: Modelling regional responses by marine pelagic ecosystems to global climate change, Geophys. Res. Lett., 29(16), 53-1-53-4, doi:10.1029/2001GL014130, 2002. 
Boyd, P. W., Watson, A. J., Law, C. S., Abraham, E. R., Trull, T., Murdoch, R., Bakker, C. E., Bowei, A. R., Buesseler, K. O., Chang, H., Charette, M., Croot, P., Downing, K., Frew, R., Gall, M., Hadfield, M., Hall, J., Harvey, M., Jameson, G., LaRoche, J., Liddicoat, M., Ling, R., Maldonado, M. T., McKay, R. M., Nodder, S., Pickmere, S., Pridmore, Rintoul, S., Safi, K., Sutton, P., Strzepek, R., Tanneberger, K., Turner, S., Waite, A., and Zeldis, J.: A mesoscale phytoplankton bloom in the polar Southern Ocean stimulated by iron fertilization, Nature, 40, 695-702, 2000.

Bolye, E. A.: What controls dissolved iron concentrations in the world ocean - A comment, Mar. Chem., 57, 163-167, 1997.

Boyle, E. A., Bergquist, B. A., Kayser, R. A., and Mahowald, N.: Iron, manganese, and lead at Hawaii Ocean Time-series station ALOHA: Temporal variability and an intermediate water hydrothermal plume, Geochimica et Cosmocimica Acta, 69, 933952, 2005

Bruland, K. W., Orians, K. J., and Cowen, J. P.: Reactive trace metals in the stratified central North Pacific, Geochimica et Cosmocimica Acta, 58, 3171-3182, 1994.

Bruland, K. W. and Lohan, M. C.: The control of trace metals in seawater, Chapt. 2, in: The Oceans and Marine Geochemistry, Vol. 6, edited by: Elderfield, H., in: Treatise on Geochemistry, edited by: Holland, H. D. and Turekian, K. K., 23-47, 2004.

Bruland, K. W., Rue, E. L., Smith, G. J., and DiTullio, G. R.: Iron, macronutrients and diatom blooms in the Peru upwelling regime: brown and blue waters of Peru, Mar. Chem., 93, 81-103, 2005.

Bucciarelli, E., Blain, S., and Treguer, P.: Iron and manganese in the wake of the Kerguelen Islands (Southern Ocean), Mar. Chem., 73, 21-36, 2001.

Burd, A. B., Jackson, G. A., Moran, S. B.: A coupled adsorptionaggregation model for the $\mathrm{POC} /{ }^{234} \mathrm{Th}$ ratio of marine particles, Deep-Sea Res. I., 47, 103-120, 2000.

Chase, Z., Johnson, K. S., Elrod, V. A., Plant, J. N., Fitzwater, S. E., Pickell, L., Sakamoto, C. M.: Manganese and iron distributions off central California influenced by upwelling and shelf width, Mar. Chem., 95, 235-254, 2005.

Christian, J. R., Verschell, M. A., Murtugudde, R., Busalacchi, A. J., and McClain, C. R.: Biogeochemical modeling of the tropical Pacific Ocean II. Iron biogeochemistry, Deep-Sea Res. II, 49, 545-565, 2002.

Clegg, S. L. and Sarmiento, J. L.: The hydrolytic scavenging of metal ions by marine particulate matter, Prog. Oceanogr., 23, 121, 1989.

Coale, K. H., Gordon, R. M., and Wang, X.: The distribution and behavior of dissolved and particulate iron and zinc in the Ross Sea and Antarctic circumpolar current along $170^{\circ} \mathrm{W}$, Deep-Sea Res. I, 52, 295-318, 2005.

Coale, K. H., Johnson, K. S., Fitzwater, S. E., Gordon, R. M., Tanner, S., Chavez, F. P., Ferioli, L., Sakamoto, C., Rogers, P., Millero, F., Steinberg, P., Nightingale, P., Cooper, D., Cochlan, W. P., Landry, M. R., Constantiou, J., Rollwagen, G., Trasvina, A., and Kudela, R.: A massive phytoplankton bloom induced by an ecosystem-scale iron fertilization experiment in the equatorial Pacific Ocean, Nature, 383, 495-501, 1996.

Coale, K. H., Johnson, K. S., Chavez, F. P., Buesseler, K. O., Barber, R. T., et al.: Southern Ocean Iron Enrichment Experiment: Carbon cycling in high- and low-Si waters, Science, 304, 408-414, 2004.
Coale, K. H., Wang, X., Tanner, S. J., and Johnson, K. S.: Phytoplankton growth and biological response to iron and zinc addition in the Ross Sea and Antarctic Circumpolar Current along $170^{\circ}$ W, Deep-Sea Res. II, 50, 635-653, 2003.

Collins, W. D., Bitz, C. M., Blackmon, M. L., Bonan, G. B., Bretherton, C. S., Carton, J. A., Chang, P., Doney, S. C., Hack, J. J., Henderson, T. B., Kiehl, J. T., Large, W. G., McKenna, D. S., Santer, B. D., and Smith, R. D.: The Community Climate System Model Version 3 (CCSM3), J. Climate, 19(11), 2122-2143, 2006.

Conkright, M. E., Locarnini, R. A., Garcia, H. E., O’Brien, T. D., Boyer, T. P., Stevens, C., and Antonov, J. I.: World Ocean Atlas 2001: Objective analysis, data statistics, and figures, CDROM documentation, National Oceanographic Data Center, Silver Spring, MD, 2002.

Cullen, J. T., Bergquist, B. A., and Moffett, J. W.: Thermodynamic characterization of the partitioning of iron between soluble and colloidal species in the Atlantic Ocean, Mar. Chem., 98, 295303, 2006.

de Barr, J. W. H., Boyd, P. W., Coale, K. H., Landry M. R., Tsuda, A., Assmy, P., Bakker, D. C. E., Boze, Y., Barber, R. T., Brzezinski, M. A., Buesseler, K. O., Boyé, M., Croot, P. L., Gervais, F., Gorbunov, M. Y., Harrison, P. J., Hiscock, W. T., Laan, P., Lancelot, C., Law, C. S., Levasseur, M., Marchetti, A., Millero, F. J., Nishioka, J., Nojiri, Y., van Oijen, T., Riebesell, U., Rijkenberg, M. J. A., Saito, H., Takeda, S., Timmermans, K. R., Veldhuis, M. J. W., Waite, A. M., and Wong, C. S.: Synthesis of iron fertilization experiments: From the Iron age in the Age of Enlightenment, J. Geophys. Res.-Oceans, 110, C09S16, doi:10.1029/2004JC002601, 2005.

de Baar, H. J. W. and de Jong, J. T. M.: Distributions, sources and sinks of iron in seawater, in: Biogeochemistry of Iron in Seawater, edited by: Turner, D. and Hunter, K. A., IUPAC Book Series on Analytical and Physical Chemistry of Environmental Systems, 7, 123-253, 2001.

de Baar, H. J. W., de Jong, J. T. M., Nolting, R. F., Timmermans, K. R., van Leeuwe, M. A., Bathmann, U., Rutgers van der Loeff, M., and Sildam, J.: Low dissolved Fe and the absence of diatom blooms in remote Pacific waters of the Southern Ocean, Mar. Chem., 66, 1-34, 1999.

Doney, S. C. and Ducklow, H. W.: A decade of synthesis and modeling in the US Joint Global Flux Study, Deep-Sea Res. II, 53 451-458, 2006.

Doney, S. C., Lindsay, K., Fung, I., and John, J.: Variability in a stable, 1000-yr coupled climate-carbon simulation, J. Climate, 19, 3033-3054, 2006.

Dutkiewicz, S., Follows, M., and Parekh, P.: Interactions of the iron and phosphorus cycles: A three-dimensional model study, Global Biogeochem. Cy., 19, GB1021, doi:10.1029/2004GB002342, 2005.

Elrod, V. A., Berelson, W. M., Coale, K. H., and Johnson, K. S.: The flux of iron from continental shelf sediments: A missing source of global budgets. Geophys. Res. Lett., 31, L12307, doi:10.1029/2004GL020216, 2004.

Falkowski, P. G.: Evolution of the nitrogen cycle and its influence on the biological sequestration of CO2 in the ocean, Nature, 387 , 272-275, 1997.

Fan, S. M., Moxim, W. J., and Levy II, H.: Aeolian input of bioavailable iron to the ocean, Geophys. Res. Lett., 33, L07602, 
doi:10.1029/2005GL024852, 2006.

Fitzwater, S. E., Coale, K. H., Gordon, R. M., Johnson, K. S., and Ondrusek, M. E.: Iron deficiency and phytoplankton growth in the equatorial Pacific. Deep-Sea Res. II, 43, 995-1015, 1996.

Frew, R. D., Hutchins, D. A., Nodder, S., Sanudo-Wilhelmy, S., Tovar-Sanchez, A., Leblanc, K., Hare, C. E., and Boyd, P. W.: Particulate iron dynamics during FeCycle in subantarctic waters southeast of New Zealand. Global Biogeochem. Cy., 20, GB1S93, doi:10.1029/2005GB002558, 2006.

Fung, I. Y., Meyn, S. K., Tegen, I., Doney, S. C., John, J. G., and Bishop, J. K. B.: Iron supply and demand in the upper ocean, Global Biogeochem. Cy., 14, 281-295, 2000.

Gregg, W., Ginoux, P., Schopf, P. S., and Casey, N. W.: Phytoplankton and iron: validation of a global three-dimensional ocean biogeochemical model, Deep-Sea Res. II, 50, 3143-3169, 2003.

Gruber, N.: The dynamics of the marine nitrogen cycle and its influence on atmospheric $\mathrm{CO}_{2}$ variations, in: The Ocean Carbon Cycle, edited by: Follows, M. and Oguz, T., Kluwer Academic Publishers, Netherlands, 97-148, 2004.

Guo, L., Hung, C. C., Santschi, P. H., and Walsh, I. D.: ${ }^{234}$ Th scavenging and its relationship to acid polysaccharide abundance in the Gulf of Mexico, Mar. Chem., 78, 103-119, 2002.

Honeyman, B. D., Balistrieri, L. S., and Murray, J. W.: Oceanic trace metal scavenging: the importance of particle concentration, Deep-Sea Res., 35, 227-246, 1988.

Honeyman, B. D. and Santschi, P. H.: A Brownian-pumping model for oceanic trace-metal scavenging: evidence from Th isotopes, J. Mar. Res., 47, 951-992, 1989.

Johnson, K., Gordon, M. R., and Coale K. H.: What controls dissolved iron concentrations in the world ocean?, Mar. Chem., 57, 137-161, 1997a.

Johnson, K., Gordon, M. R., and Coale, K. H.: What controls dissolved iron concentrations in the world ocean? - Authors closing comments, Mar. Chem., 57, 181-186, 1997b.

Johnson, K. S., Chavez, F. P., and Friederich, G. E. Continentalshelf sediment as a primary source of iron for coastal phytoplankton, Nature, 398, 697-700, 1999.

Johnson, K. S., Elrod, V. A., Fitzwater, S. E., Plant, J. N., Chavez, F. P., Tanner, S. J., Gordon, R. M., Westphal, D. L., Perry, K. D., Wu, J., and Karl, D. M.: Surface ocean-lower atmosphere interactions in the Northeast Pacific Ocean Gyre: Aerosols, iron, and the ecosystem response, Global Biogeochem. Cy., 17, 1063, doi:10.1029/2002GB002004, 2003.

Johnson, W. K., Miller, L. A., Sutherland, N. D., and Wong, C. S.: Iron transport by mesoscale Haida eddies in the Gulf of Alaska, Deep-Sea Res. II, 52, 933-953, 2005.

Klaas, C. and Archer, D. E.: Association of sinking organic matter with various types of mineral ballast in the deep sea: Implications for the rain ratio, Global Biogeochem. Cy., 16, 1116, doi:10.1029/2001GB001765, 2002.

Krishnamurthy, A., Moore, J. K., Zender, C. S., and Luo, C: The Effects of Atmospheric Inorganic Nitrogen Deposition on Ocean Biogeochemistry, J. Geophys. Res., 112, G02019, doi:10.1029/2006JG000334, 2007.

Kudo, I., Noiri, Y., Nishioka, J., Taira, Y., Kiyosawa, H., and Tsuda, A.: Phytoplankton community response to $\mathrm{Fe}$ and temperature gradients in the NE (SERIES) and NW (SEEDS) subarctic Pacific Ocean, Deep-Sea Res. II, 53, 2201-2213, 2006.

Lam, P. J., Bishop, J. K. B., Henning, C. C., Marcus, M.
A., Waychunas, G. A., and Fung, I. Y.: Wintertime phytoplankton bloom in the subarctic Pacific supported by continental margin iron, Global Biogeochem. Cy., 20, GB1006, doi:10.1029/2005GB002557, 2006.

Large, W. G. and Yeager, S. G.: Diurnal to decadal global forcing for ocean and sea-ice models: the data sets and flux climatologies, NCAR Technical Note NCAR/TN-460+STR, 111 pp., 2004.

Le Quéré, C., Harrison, S. P., Prentice, I. C., Buitenhuis, E. T., Aumont, O., et al.: Ecosystem dynamics based on plankton functional types for global ocean biogeochemistry models, Global Change Biol., 11, 2016-2040, 2005.

Lefèvre, N. and Watson, A. J.: Modeling the geochemical cycle of iron in the oceans and its impact on atmospheric $\mathrm{CO} 2$ concentrations, Global Biogeochem. Cy., 13, 727-736, 1999.

Löscher, B. M., de Baar, H. J. W., de Jong, J. T. M., and Goeyens, L.: The distribution of Fe in the Antarctic Circumpolar Current, Deep Sea-Res. II., 44, 143-187, 1997.

Luo, C., Mahowald, N., and del Corral, J.: Sensitivity study of meteorological parameters on mineral aerosol mobilization, transport and distribution, J. Geophys. Res., 108(D15), 4447, doi:10.1029/2003JD0003483, 2003.

Luo, C., Mahowald, N. M., Meskidze, N., Chen, Y., Siefert, R. L., Baker, A. R., and Johansen, A. M.: Estimation of iron solubility from observations and a global aerosol model, J. Geophys. Res., 110, D23307, doi:10.1029/2005D006059, 2005.

Luther III, G. W. and Wu, J.: What controls dissolved iron concentrations in the world ocean? - a comment, Mar. Chem., 57, 173-179, 1997.

Mackey, D. J., O'Sullivan, J. E., and Watson, R. J.: Iron in the western Pacific: a riverine or hydrothermal source for iron in the Equatorial Undercurrent?, Deep-Sea Res. I, 49, 877-893, 2002.

Mahowald, N. M., Baker, A. R., Bergametti, G., Brooks, N., Duce, A., Jickells, T. D., Kubliay, N., Prospero, J. M., and Tegen, I.: Atmospheric global dust cycle and iron inputs to the ocean, Global Biogeochem. Cy., 19, GB4025, doi:10.1029/2004GB002402, 2005.

Martin, J. H.: Iron as a limiting factor in oceanic productivity, in: Primary Productivity and Biogeochemical Cycles in the Sea, edited by: Falkowski, P. G. and Woodhead, A. D., Plenum Press, New York, 123-137, 1992.

Martin, J. H., Gordon, R. M., and Fitzwater, S. E.: The case for iron, Limnol. Oceanogr., 36, 1793-1802, 1991.

McKay, R. M. L., Wilhelm, S. W., Hall, J., Hutchins, D. A., AlRshaidat, M. M. D., Mioni, C. E., Pickmere, S., Porta, D., and Boyd, P. W.: Impact of phytoplankton on the biogeochemical cycling of iron in subantarctic waters southeast of New Zealand during FeCycle, Global Biogeochem. Cy., 19, GB4S24, doi:10.1029/2005GB002482, 2005.

Measures, C. I. and Vink, S.: Seasonal variations in the distribution of $\mathrm{Fe}$ and $\mathrm{Al}$ in the surface waters of the Arabian Sea, Deep-Sea Res. II, 46, 1597-1622, 1999.

Measures, C. I. and Vink, S.: Dissolved Fe in the upper waters of the Pacific sector of the Southern Ocean, Deep-Sea Res. II, 48, 3913-3941, 2001.

Michaels, A. F., Karl, D. M., and Capone, D. G.: Elemental stoichiometry, new production, and N fixation, Oceanography, 14(4), 68-77, 2001.

Moore, J. K., Doney, S. C., Kleypas, J. C., Glover, D. M., and Fung, 
I. Y.: An intermediate complexity marine ecosystem model for the global domain, Deep-Sea Res. II, 49, 403-462, 2002a.

Moore, J. K., Doney, S. C., Glover, D. M., and Fung, I. Y.: Iron cycling and nutrient limitation patterns in surface waters of the world ocean, Deep-Sea Res. II, 49, 463-508, 2002 b.

Moore, J. K., Doney, S. C., and Lindsay, K.: Upper ocean ecosystem dynamics and iron cycling in a global threedimensional model, Global Biogeochem. Cy., 18, GB4028, doi:10.1029/2004GB002220, 2004.

Moore, J. K., Doney, S. C., Lindsay, K., Mahowald, N., and Michaels, A. F.: $\mathrm{N}$ fixation amplifies the ocean biogeochemical response to decadal timescale variations in mineral dust deposition, Tellus B, 58B, 560-572, 2006.

Moore, J. K. and Doney, S. C.: Iron availability limits the ocean nitrogen inventory stabilizing feedbacks between marine denitrification and nitrogen fixation, Global Biogeochem. Cy., 21, GB2001, doi:10.1029/2006GB002762.

Nishioka, J., Takeda, S., Wong, C. S., and Johnson, W.K .: Sizefractionated iron concentrations in the northeast Pacific Ocean: distribution of soluble and colloidal iron, Mar. Chem., 74, 157179, 2001.

Nishioka, J., Takeda, S., de Baar, H. J. W., Croot, P. L., Boye, M., Laan, P., and Timmermans, K. R.: Changes in the concentration of iron in different size fractions during an iron fertilization experiment in the open Southern Ocean, Mar. Chem., 95, 51-63, 2005.

Parekh, P., Follows, M. J., and Boyle, E. A.: Modeling the global ocean iron cycle, Global Biogeochem. Cy., 18, GB1002, doi:10.1029/2003GB002061, 2004.

Parekh, P., Follows, M. J., and Boyle, E. A.: Decoupling of iron and phosphate in the global ocean, Global Biogeochem. Cy., 19, GB2020, doi:10.1029/2004GB002280, 2005.

Parekh, P., Follows, M. J., Dutkiewicz, S., and Ito, T.: Physical and biological regulation of the soft tissue carbon pump, Paleoceanography, 21, PA3001, doi:10.1029/2005PA001258, 2006.

Passow, U., Dunne, J., Murray, J. W., Balistrieri, L., and Alldredge, A. L.: Organic carbon to ${ }^{234} \mathrm{Th}$ ratios of marine organic matter, Mar. Chem., 100, 323-336, 2006.

Price, N. M., Ahner, B. A., and Morel, F. M. M.: The equatorial Pacific Ocean: Grazer-controlled phytoplankton populations in an iron-limited system, Limnol. Oceanogr., 39, 520-534, 1994.

Quigley, M. S., Santschi, P. H., Guo, L., Honeyman, B. D.: Sorption irreversibility and coagulation of $234^{T h}$ with marine organic matter, Mar. Chem., 76, 27-45, 2001.

Reddy, T. E. and Arrigo, K. R.: Constraints on the extent of the Ross Sea phytoplankton bloom, J. Geophys. Res., 111, C07005, doi:10.1029/2005JC003339, 2006.

Rue, E. and Bruland, K.: Complexation of iron (III) by natural organic ligands in the central North Pacific as determined by a new competitive ligand equilibration/adsorptive cathodic stripping voltammetric method, Mar. Chem., 50, 117-138, 1995.

Rue, E. and Bruland, K.: The role of organic complexation on ambient iron chemistry in the equatorial Pacific Ocean and the response of a mesoscale iron addition experiment, Limnol. Oceanogr., 42, 901-910, 1997.

Santschi, P. H., Murray, J. W., Baskaran, M., Benitez-Nelson, C. R., Guo, L. D., Hung, C. C., Lamborg, C., Moran, S. B., Passow, U., and Roy-Barman, M.: Thorium speciation in seawater, Mar. Chem., 100, 250-268, 2006.
Savoye, N., Benitez-Nelson, C., Burd, A. B., Cochran, J. K., Charette, M., Buesseler, K. O., Jackson, G. A., Roy-Barman, M., Schmidt, S., and Elskens, M.: ${ }^{234}$ Th sorption and export models in the water column: A review, Mar. Chem., 100, 234-249, 2006.

Sedwick, P. N., Church, T. M., Bowie, A. R., Marsay, C. M., Ussher, S. J., Achilles, K. M., Lethaby, P. J., Johnson, R. J., Sarin, M. M., and McGillicuddy, D. J.: Iron in the Sargasso Sea (Bermuda Atlantic Time-series Study region) during summer: Eolian imprint, spatiotemporal variability, and ecological implications, Global Biogeochem. Cy., 19, GB4006, doi:10.1029/2004GB002445, 2005.

Sunda, W. G.: Control of dissolved iron concentrations in the world ocean: A comment, Mar. Chem., 57, 169-172, 1997.

Sunda, W. G. and Huntsman, S. A.: Interrelated influence of iron, light, and cell size on marine phytoplankton growth, Nature, 390, 389-392, 1997.

Taylor, K. E.: Summarizing multiple aspects of model performance in a single diagram, J. Geophys. Res., 106, 7183-7192, 2001.

Timmermans, K. R., van der Wagt, B., and de Baar, H. J. W.: Growth rates, half saturation constants, and silicate, nitrate, and phosphate depletion in relation to iron availability of four large open ocean diatoms from the Southern Ocean, Limnol. Oceanogr., 46, 260-266, 2004.

Tovar-Sanchez, A., Sañudo-Wilhelmy, S. A., Kustka, A. B., Agusti, S., Dachs, J., Hutchins, D. A., Capone, D. G., Duarte, C. M.: Effects of dust deposition and river discharges on trace metal composition of Trichodesmium spp. in the tropical and subtropical North Atlantic Ocean, Limnol. Oceanogr., 51(4), 1755-1761, 2006.

Tsuda, A., Takeda, S., Saito, H., Nishioka, J., Nojiri, Y., Kudo, I., Kiyosawa, H., Shiomoto, A., Imai, K., Ono, T., Shimamoto, A., Tsumune, D., Yoshimura, T., Aono, T., Hinuma, A., Kinugasa, M., Suzuki, K., Sohrin, Y., Noiri, Y., Tani, H., Deguchi, Y., Tsurushima, N., Ogawa, H., Kimio Fukami, K., Kuma, K., and Saino, T.: A mesoscale iron enrichment in the western Subarctic Pacific induces a large centric diatom bloom, Science, 300, 958-961, 2003.

Twining, B. S., Baines, S. B., Fisher, N. S., Langry, M.R .: Cellular iron contents of plankton during the Southern Ocean Iron Experiment (SOFeX), Deep-Sea Res. I., 51, 1827-1850, 2004.

US Department of Commerce: 2-minute global gridded relief data. National Oceanographic and Atmospheric Administration, National Geophysical Data Center, 2006.

van den Berg, C.: Evidence for organic complexation of iron in seawater, Mar. Chem., 50, 139-157, 1995.

Wells, M. L. and Goldberg, E. D.: Colloid aggregation in seawater, Mar. Chem., 41, 353-358, 1993.

Wen, L. S., Jiann, K. T., and Santschi, P. H.: Physicochemical speciation of bioactive metals $(\mathrm{Cd}, \mathrm{Cu}, \mathrm{Fe}, \mathrm{Ni})$ in the oligotrophic South China, Sea. Mar. Chem., 101, 104-129, $2006 .$.

Wu, J., Boyle, E., Sunda, W., and Wen, L.S .: Soluble and colloidal iron in the oligotrophic North Atlantic and North Pacific, Science, 293, 847-849, 2001.

$\mathrm{Wu}$, J. and Boyle, E.: Iron in the Sargasso Sea: Implications for the processes controlling dissolved $\mathrm{Fe}$ distribution in the ocean, Global Biogeochem. Cy., 16(4), 1086, doi:10.1029/2001GB001453, 2002.

$\mathrm{Wu}$, J. and Luther, G.: Complexation of Fe(III) by natural organic ligands in the Northwest Atlantic Ocean by a competitive ligand 
equilibration method and kinetic approach, Mar. Chem., 50, 159177, 1995.

Yeager, S. G., Large, W. G., Hack, J. J., and Shields, C. A.: The Low Resolution CCSM3, J. Climate, 17, 2545-2566, 2006.
Zender, C. S., Bian, H., and Newman, D.: The Mineral Dust Entrainment And Deposition (DEAD) model: Description and 1990s dust climatology, J. Geophys. Res., 108(D14), 4416, doi:10.1029/2002JD002775, 2003. 